\title{
Photoprocesses of coordination compounds and dyes in solution and nanoporous materials: Evolution from milliseconds to femtoseconds ${ }^{\#}$
}

\author{
P NATARAJAN*, K DURAIMURUGAN and K SENTHIL KUMAR \\ National Centre for Ultrafast Processes, University of Madras, Taramani Campus, Chennai 600 113, India \\ e-mail: pnatrajan@hotmail.com
}

MS received 14 April 2011; revised 23 July 2011; accepted 29 July 2011

\begin{abstract}
The photoredox reactions of cobalt(III), nickel(II) complexes and organic dyes are reviewed with particular emphasis on using flash photolysis methods to identify the transients in the time scale from milliseconds to subpicoseconds. The excitation flash radiation initially was limited to flash lamps with a time resolution to study the decay of the excited states and the fast reactions of photo produced transients in milliseconds and microseconds. Some of the photolysis reactions investigated provide details in real time including the thermal reactions of molecular oxygen with cobalt(II) amine systems and the cobalt (III) alkyl complex formation on photolysis of cobalt(III) aminoacid complexes. Photoredox reactions of thiazine and safranine dyes are investigated using time resolved absorption and emission techniques in solution and on encapsulation in micro and mesoporous host materials. Picosecond and femtosecond diffuse reflectance fluorescence investigations in the porous solid host materials show intramolecular proton transfer reactions of the dyes and deprotonation of the dyes in the excited states. Photosensitization of nanoparticles of semiconductors, anatase $\mathrm{TiO}_{2}$ and $\mathrm{ZnO}$ by the excited states of dyes in meso and microporous silicate hosts is investigated using pico and femtosecond fluorescence and transient absorptions techniques and the results are reviewed.
\end{abstract}

Keywords. Photochemistry; laser flash photolysis; meso and micro porous silicates; thionine; phenosafranine; polyelectrolytes; nano porous materials.

\section{Introduction}

Photochemistry is an area of intensive research in the last four decades spanning many other related areas from materials science to medicine. ${ }^{1}$ Chemical transformation induced by visible light was of interest to synthesize new compounds using light as one of the reactants. Photosynthesis has always been looked at as the evolutionary model to use light as a source to produce value added chemicals. ${ }^{2-5}$ Early researchers used sunlight to effect photochemical reactions and later on visible and ultraviolet light sources have replaced sun light. Photochemical research was an intensive area of research for aiding in the production of primarily organic compounds via photochemical route. Although the molecular structure and the electronic excited states of molecules have been of intense discussion, the interpretation of photochemical reactions has not been

\footnotetext{
${ }^{*}$ For correspondence

${ }^{\#}$ The article is based on the Gold Medal lecture delivered at Chemical Research Society of India (CRSI) meeting; Bhubaneshwar 2011 by P. Natarajan.
}

clearly indicated using the approximation methods of quantum theory. ${ }^{6-8}$ Earlier attempts to invoke the singlet and triplet states of simple aromatic compounds started with the characterization of organic photochemistry linking the molecular structure information from quantum theory and experimental results from steady state photochemistry. Kasha has been the fore runner to interpret the photochemical reactions invoking the concepts of excited triplet states, intersystem crossing and other excited state relaxation processes. ${ }^{9-12}$

During the middle of last century Norrish and Porter have invented flash photolysis technique for the understanding of the light induced processes in real time. Since then photochemistry has taken a new level of intense activity with the theoretical formulation of Woodward-Hoffman rules; the interpretation of certain organic photochemical transformations has been very successful with insight into the structural nature of excited states. Many significant and epoch-making developments in photochemistry have emerged with many organic, inorganic and biological systems using flash photolysis technique since $1960 .{ }^{13-17}$ Several outstanding researchers have now invoked theoretical 
formulations using the available spectroscopic details of organic systems, to understand organic photochemical processes. ${ }^{18-21}$ Understanding the naturally occurring light-induced processes in photosynthesis in all life forms, in vision and in the environment was still a formidable task. During the last three decades photochemistry has emerged into a vast field of research with the advent of ultrafast lasers for photochemical and photophysical research.

Photochemistry of coordination compounds was investigated from an altogether different perspective. Well-known photochemical systems of uranyl oxalate and ferric oxalate are known to undergo rapid decomposition in visible light resulting in redox reactions since a long time. These systems have been used by photochemists in general for measuring the intensity of steady state irradiation sources as actinometers to obtain the extent and quantification of the product yields in terms of the intensity of the light source used. The photoredox reactions of the ferric oxalate and uranyl oxalate have been well-documented. ${ }^{2-7}$ Understanding of the primary processes of the photoredox reactions of the uranyl oxalate and ferric oxalate has been attempted with some of the very early flash photolysis experiments in the sixties. However, application of ligand field interpretation of the excited states for the understanding of the photochemical reactions of chromium and cobalt complexes was the result of the pioneer and outstanding contributions from Adamson since the fifties. ${ }^{8}$ Many of the early advances made in the interpretation of the photochemical processes occurring in coordination compounds are due to the steady state photochemical research using conventional light sources primarily the mercury and xenon lamps.

The advances made in the real time resolution of the physical and chemical processes occurring from the excited states of molecules have rapidly pushed the frontiers of photochemical research to unravel the processes occurring at nanosecond levels to femtosecond levels by the end of the last century. The advances made in the application of different microscopic techniques combined with time resolved methods limiting to femto second time domain have led to the emergence of new areas in radiation-induced chemistry of the supramolecular and nanomaterial systems and in molecular biology. Photochemical research in the present context has encompassed vast areas of different aspects of photobiological systems in molecular biology and medicine, design of novel and functional materials for lightinduced new energy systems using solar energy as the source and design of advanced photonic materials for information storage and retrieval. The term photochemical research has now moved into the new areas of ultrafast photoprocesses, display systems, materials for energy generation and storage and so on.

An overview of the photochemical processes of coordination compounds investigated in homogeneous solutions using time resolved absorption and emission spectral techniques is presented in this review with particular emphasis of the work carried out in the research group at NCUFP. The reactions investigated are more focused with reference to charge transfer processes at the excited states of metal complexes and organic dyes. Charge transfer processes are of importance for application in photosynthetic mimics of biological systems. With the same focus the excited state electron transfer processes of well-known organic dyes are studied using flash photolysis methods from milliseconds to picosecond time domains. The review is concerned on the use of the time resolved absorption and emission spectral studies of metal complexes and some organic dyes in condensed phase medium and in polymeric environment and more recently using micro and mesoporous host materials for the light absorbing systems. The systems which are investigated are broadly classified into the following categories:

(i) Photosensitization of cobalt dinuclear complexes by $\mathrm{Ru}(\mathrm{bpy})_{3}^{2+}$ excited state.

(ii) Oxygenation reactions of cobalt(II)amines studied by in-situ generation of cobalt(II) systems on the photoreduction of cobalt(III) complexes.

(iii) Photoformation of organo cobalt(III) complexes and the investigations of the formation of intermediates by time resolved absorption processes.

(iv) Photooxidation of nickel macrocyclic complexes on excitation in the CTTS band.

(v) Excited state redox processes of organic dyes covalently bound to synthetic polymers and investigations of the excited state processes of organic dyes in polymeric micro heterogeneous environment.

In recent years excited state processes of organic dyes confined to the nanopores of micro and mesoporous silicate hosts have been investigated in the pico and femtosecond time frame. ${ }^{21 \mathrm{~b}}$ Photo processes of the dyes and the photosensitization of nanoparticles of semiconductors embedded in the nanopores of the silicate hosts are currently investigated with the view to understand and design materials for visible light energy conversion. ${ }^{21 \mathrm{c}}$ The focus of this review is the evolution of the use of the time resolved absorption and emission techniques in the laboratories at the University of Madras for the study 
of excited state processes from fast to ultrafast time scales.

Ruthenium(II)trisbipyridyl ion, $\mathrm{Ru}(\mathrm{bpy})_{3}^{2+}$, was used as a photosensitizer for the first time in 1970 to sensitize platinum(II) complex by Demas and Adamson $^{22}$ and subsequently for the photosensitization of cobalt(II)amine complexes by Natarajan and Endicott. ${ }^{23}$ Initially it was suggested that the photosensitization process is an energy transfer process from the $\mathrm{Ru}(\mathrm{bpy})_{3}^{2+}$ emitting state to the low-lying excited states of metal complexes. However, later Gafney and Adamson have proposed an excited state electron transfer pathway for the photosensitization process. Indeed the controversy was finally resolved ${ }^{24}$ using hexaaquoferric ion as the quencher of the $\mathrm{Ru}(\mathrm{bpy})_{3}^{2+}$ ion where it was shown unequivocally that the photosensitization process from the $\mathrm{Ru}(\mathrm{bpy})_{3}^{2+}$ ion is indeed a well-defined excited state electron transfer process. Since that time $\mathrm{Ru}(\mathrm{bpy})_{3}^{2+}$ ion and other ruthenium polypyridyl and related compounds have been extensively investigated for the understanding of electron transfer process and for developing a photoelectrochemical cell for the utilization of solar energy and for other applications. ${ }^{21 b}$ Photochemistry of this complex, $\mathrm{Ru}(\mathrm{bpy})_{3}^{2+}$ and other related systems have been published in more than 10,000 publications till date.

Initially investigations have been focused to understand the photosensitization of dinuclear cobalt(III) amine and polypyridyl systems using the excited state $\mathrm{Ru}(\mathrm{bpy})_{3}^{2+}$ ion by Natarajan and his group. ${ }^{25}$

\section{Photoredox processes of cobalt(II) and nickel(II) complexes in homogenous solution}

\subsection{Photosensitization of cobalt dinuclear complex by excited state of $R u(b p y)_{3}^{2+}$ ion}

Quenching of the excited state of $\mathrm{Ru}(\mathrm{bpy})_{3}^{2+}$ by superoxo-bridged dinuclear cobalt(III) complexes with amine and polypyridyl ligands are investigated ${ }^{25}$ by luminescence quenching studies and by product analysis (scheme 1).

Bimolecular quenching constants are determined to be of the order of $10^{9} \mathrm{M}^{-1} \mathrm{~s}^{-1}$, which are somewhat higher than the value expected on formal charge basis. Formation of $\mathrm{Ru}(\mathrm{bpy})_{3}^{3+}$ and cobaltous ion as products of photosensitization occurs in low yields and this reaction is explained to occur in an energy-transfer pathway. The energy-transfer pathway accounts as a minor pathway for about $10 \%$ of the quenching events whereas

\author{
$\left[\left(\mathrm{NH}_{3}\right)_{5} \mathrm{Co}-\mathrm{O}_{2}-\mathrm{Co}\left(\mathrm{NH}_{3}\right)_{5}\right]\left(\mathrm{NO}_{3}\right)_{5}$<smiles>CC(C)(C)CNC(=O)OC(C)(C)C</smiles> \\ 2<smiles>CCONC(=O)OCC(=O)O</smiles> \\ 3, $\mathrm{L}=$ ethylenediamine \\ 4, $\mathrm{L}=2,2^{\prime}$-bipyridine \\ 5, $\mathrm{L}=1,10$-phenanthroline
}

$\mathbf{E}_{\mathbf{0}}, \mathbf{V}$

${ }^{*} \mathbf{R u}(\mathrm{bpy})_{3}{ }^{2+} / \mathbf{R u}(\mathrm{bpy})_{3}{ }^{3+}$

${ }^{*} \mathbf{R u}(\mathrm{bpy})_{3}{ }^{2+} / \mathbf{R u}(\mathrm{bpy})_{3}{ }^{+}$

$\operatorname{Ru}(\text { bpy })_{3}{ }^{2+} / \operatorname{Ru}(\text { bpy })_{3}{ }^{3+}$

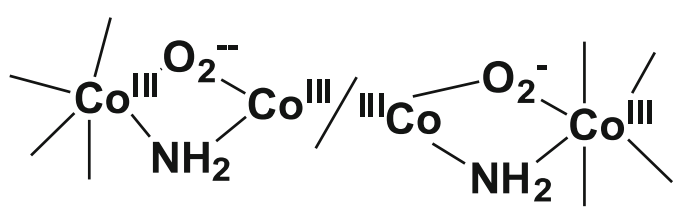

Scheme 1. Photosensitization of dinuclear cobalt(III) complexes.

the excited-state electron-transfer process accounts for $90 \%$ of the quenching. The back redox reaction which follows the energy-transfer pathway leads to the products formed in steady state photolysis studies. ${ }^{26}$

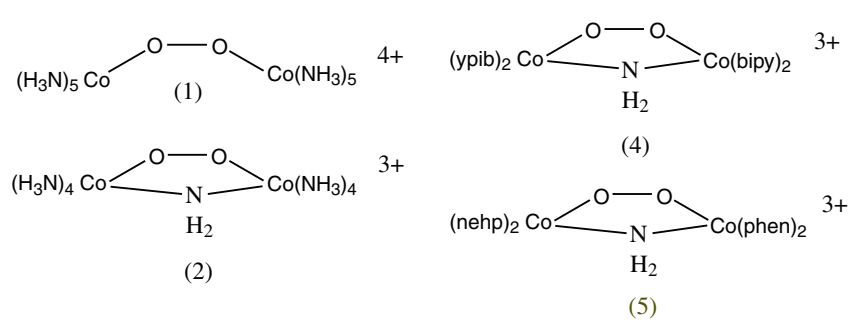

In a related study self exchange rate constants for electron transfer processes in the binuclear cobalt(III) complexes, $\mu$-peroxo-cobalt(III)complexes $\left[\left(\mathrm{H}_{3} \mathrm{~N}\right)_{5} \mathrm{Co}\right.$ $\left.\left(\mu-\mathrm{O}_{2}\right) \mathrm{Co}\left(\mathrm{NH}_{3}\right)_{5}\right]^{4+}(1), \quad\left[\left(\mathrm{H}_{3} \mathrm{~N}\right)_{4} \mathrm{Co}\left(\mu-\mathrm{O}_{2}\right)\left(\mu-\mathrm{NH}_{2}\right) \mathrm{Co}\right.$ 
$\left.\left(\mathrm{NH}_{3}\right)_{4}\right]^{3+}(2), \quad\left[(\mathrm{L}-\mathrm{L})_{2} \mathrm{Co}\left(\mu-\mathrm{O}_{2}\right)\left(\mu-\mathrm{NH}_{2}\right) \mathrm{Co}(\mathrm{L}-\mathrm{L})_{2}\right]^{3+}$ [L-L= ethylenediamine(3)], $\mathrm{L}-\mathrm{L}=2,2^{\prime}$-bipyridyl(4) and $\mathrm{L}-\mathrm{L}=1,10$-phenanthroline (5)] have been investigated. The reactants are generated by the electron-transfer quenching of the excited state of $\left[\mathrm{Ru}(\mathrm{bipy})_{3}\right]^{2+}$ by the corresponding $\mu$-superoxo-complexes using flash photolysis. The half-wave potentials measured by polarography for complexes (3), (4), and (5) are determined to be $1.00 \pm 0.05,1.04 \pm 0.05$, and $1.04 \pm 0.05 \mathrm{~V}$ respectively. The observed rate constants are used to obtain the self-exchange electron-transfer rate constants for the bridged cobalt(III) complexes. The Marcus cross relationship was used to predict the rate constants determined earlier for the electron-transfer reactions between the corresponding peroxo analog of (3) and the superoxo-forms of complexes (1), (4), and (5). The results are tabulated in table 1 .

\subsection{Formation of cobalt(II) alkyl complexes on photolysis of amino acid coordinated cobalt(III) complexes}

Cobalt(III) complexes of the type $[\mathrm{Co}(\mathrm{bpy})(\mathrm{Am})(\mathrm{AA})]^{2+}$, where bpy is 2,2'-bipyridine, Am is ethylenediamine or propylenediamine and $\mathrm{AA}$ is an amino acid, on photolysis in aqueous solution give rise to the formation of cobalt(III)-alkyl complexes. In all the cases investigated, flash photolysis studies are used to reveal the kinetics of the formation of the cobalt(III)-alkyl complex and subsequent reactions. In the case of the $\left[\mathrm{Co}(\mathrm{bpy})_{2}(\mathrm{gly})\right]^{2+}$, a stable cobalt(III)-alkyl complex is formed on photolysis as reported earlier, ${ }^{27}$ while in all the other cases the cobalt(III)-alkyl compound formed is found to decompose. The kinetics of the decomposition of the complexes has been investigated under different condition of $\mathrm{pH}$. It is observed that when two polypyridyl ligands are present in the coordination sphere, the cobalt(III)alkyl complex formed is stabi-

Table 1. Self-exchange electron-transfer rate constants for the superoxo- with the peroxo-complexes. ${ }^{26}$

\begin{tabular}{llcc}
\hline Complex & $\mathrm{E}_{1 / 2}, \mathrm{~V}$ & $\mathrm{~K}_{12}$ & $\mathrm{k}_{12} \mathrm{dm}^{3} \mathrm{~mol}^{-1} \mathrm{~s}^{-1}$ \\
\hline 1 & 0.95 & $10^{-5.25}$ & 1.8 \\
2 & 0.75 & $10^{-4.64}$ & $1.3 \times 10^{-7}$ \\
3 & 1.0 & $10^{-4.4}$ & 0.12 \\
4 & 1.05 & $10^{-2.73}$ & $2.2 \times 10^{4}$ \\
5 & 1.05 & $10^{-2.73}$ & $3.2 \times 10^{4}$ \\
\hline
\end{tabular}

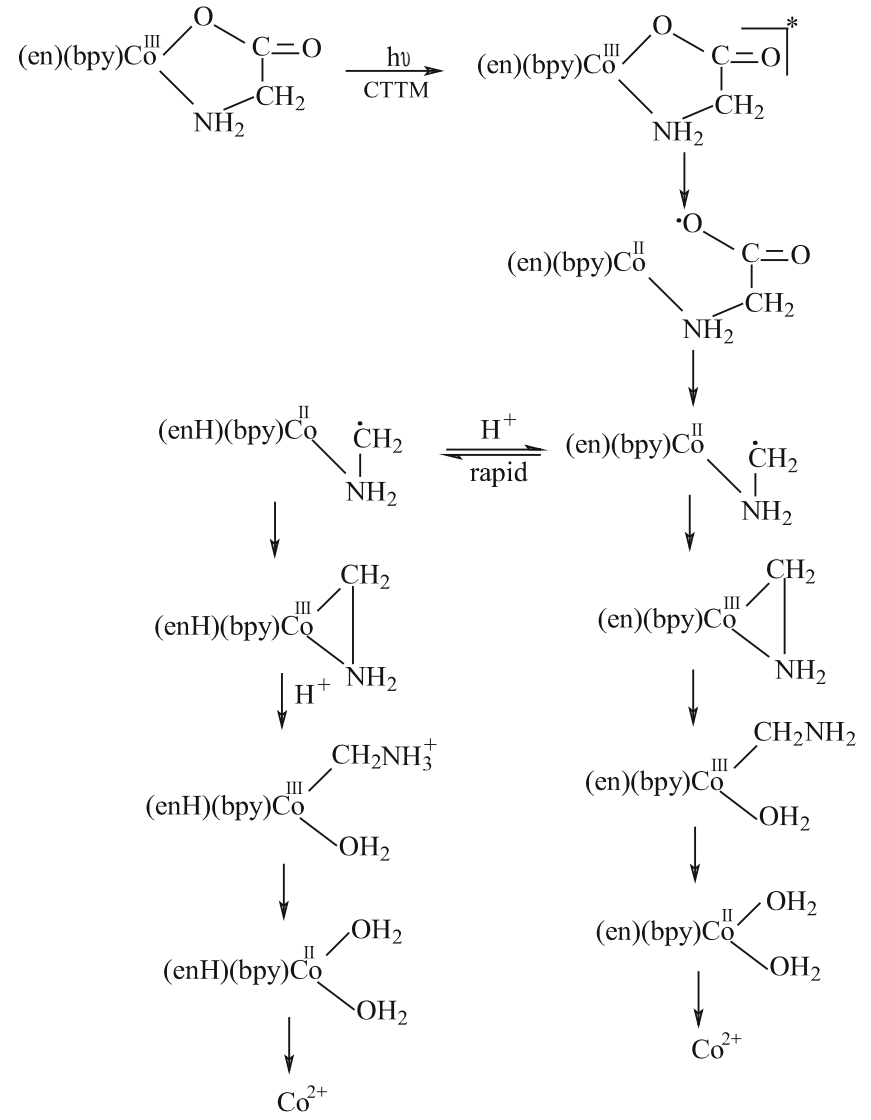

Scheme 2. Photochemical formation of the cobalt(III)alkylcomplex.

lized in solution while when only one bpy and an amine are present, the cobalt(III)-alkyl complex undergoes decomposition as shown in scheme 2. Quantum yields for cobalt(II) formation have been determined in all the cases. The presence of dissolved oxygen does not seem to affect the photochemistry in aqueous solution. The results are shown in table 2.

\subsection{Oxygenation reactions of cobalt(II) amines produced in the photoreaction of cobalt(III) complexes}

In the reactions of molecular oxygen with cobalt(II) amines, formation of $\mu$-superoxo complexes has been identified in real time on photolysis of cobalt(III) amine complexes $\left[\mathrm{Co}(\right.$ trine $\left.)\left(\mathrm{NO}_{2}\right)_{2}\right] \mathrm{ClO}_{4}$ and $[\mathrm{Co}$ (tetraen) $\left.\left(\mathrm{NO}_{2}\right)\right]\left(\mathrm{ClO}_{4}\right)_{2}$ in oxygen-saturated aqueous solution (figure 1). The oxygenation reactions have been followed by flash photolyzing the complexes and in aqueous and non-aqueous solvents and the rate constants for the formation of mononuclear superoxo complex and the $\mu$-superoxo dinuclear complex have been 
Table 2. Photolysis of cobalt(III)-amino-acid complexes in aqueous solutions (excitation using xenon flash lamp). ${ }^{27}$

\begin{tabular}{|c|c|c|c|c|}
\hline \multirow[t]{2}{*}{ Complex } & \multirow[t]{2}{*}{ PH } & \multicolumn{3}{|c|}{ Monitoring wavelength } \\
\hline & & $\begin{array}{l}410 \mathrm{~nm} \text { growth } \\
\left(\mathrm{k}_{1}\right) 10^{-3} \mathrm{~s}^{-1}\end{array}$ & $\begin{array}{c}410 \mathrm{~nm} \text { decay } \\
\left(\mathrm{k}_{2}\right) \mathrm{s}^{-1}\end{array}$ & $\begin{array}{c}220 \mathrm{~nm} \text { decay } \\
\left(\mathrm{k}_{3}\right) \mathrm{s}^{-1}\end{array}$ \\
\hline$\left[\mathrm{Co}(\mathrm{bpy})_{2}(\mathrm{gly})\right]^{2+}$ & 1.0 & 3.99 & $*$ & \\
\hline \multirow[t]{6}{*}[\mathrm{Co}(\mathrm{bpy})(\mathrm{en})(\mathrm{gly})]{$^{2+}$} & 1.0 & 3.95 & $1.34 \times 10^{3}$ & $1.29 \times 10^{-5}$ \\
\hline & 2.0 & 4.09 & $* *$ & $1.48 \times 10^{-4}$ \\
\hline & 3.0 & 4.12 & $* *$ & $3.37 \times 10^{-4}$ \\
\hline & 4.0 & 3.84 & $*$ & $1.23 \times 10^{-4}$ \\
\hline & 5.0 & 3.82 & $*$ & $2.20 \times 10^{-4}$ \\
\hline & 6.2 & 4.14 & $*$ & $1.66 \times 10^{-5}$ \\
\hline \multirow[t]{6}{*}[\mathrm{Co}(\mathrm{bpy})(\mathrm{en})(\mathrm{ala})]{$^{2+}$} & 1.0 & 4.12 & 0.59 & $3.58 \times 10^{-3}$ \\
\hline & 2.0 & 4.05 & 0.72 & $8.12 \times 10^{-3}$ \\
\hline & 3.0 & 4.37 & $* *$ & $1.01 \times 10^{-2}$ \\
\hline & 4.0 & 4.14 & $*$ & $2.74 \times 10^{-2}$ \\
\hline & 5.0 & 3.49 & $*$ & $2.27 \times 10^{-2}$ \\
\hline & 6.2 & 3.49 & $*$ & $1.51 \times 10^{-2}$ \\
\hline \multirow[t]{3}{*}{$\mathrm{Co}(\mathrm{bpy})(\mathrm{pn})(\mathrm{gly})]^{2+}$} & 1.0 & - & $1.03 \times 10^{3}$ & $1.13 \times 10^{-5}$ \\
\hline & 3.0 & - & $*$ & $6.31 \times 10^{-3}$ \\
\hline & 6.2 & - & $*$ & $5.18 \times 10^{-6}$ \\
\hline \multirow[t]{3}{*}{$\operatorname{Co}($ bpy $)(p n)($ ala $)]^{2+}$} & 1.0 & 4.08 & 0.37 & \\
\hline & 3.0 & 4.08 & 0.09 & $5.96 \times 10^{-2}$ \\
\hline & 6.2 & - & $*$ & $1.10 \times 10^{-4}$ \\
\hline
\end{tabular}

*No decay is observed

** Small decay is observed

determined at $25 \pm 1^{\circ} \mathrm{C}$. Photochemical routes for the preparation of $\mu$-superoxo cobalt(III) complexes are suggested from this study. ${ }^{29}$

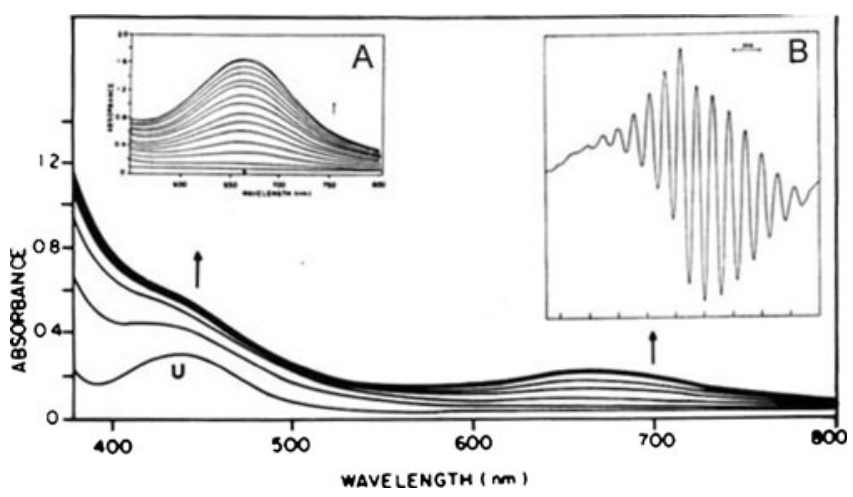

Figure 1. Steady photolysis of cis- $\left[\mathrm{Co}(\text { trien })\left(\mathrm{NO}_{2}\right)_{2}\right]^{+}$ion in oxygen-saturated aqueous solution at $4 \pm 1^{\circ} \mathrm{C}$ : $\mathrm{U}$, unirradiated solution; increase in absorbance is due to successive irradiations; (inset A) expansion of the above region, 500$800 \mathrm{~nm}$; (inset B) X-band ESR spectrum of the irradiated solution containing $50 \% \mathrm{HClO}_{4}$ at $77 \mathrm{~K}^{29}$

\subsection{Redox reactions of $\mu$-superoxo cobalt(III)} complexes by free radicals and uncommon metal ions

Reactions of the dioxygen coordinated metal complexes are of interest as mimics to understand a large number of metabolic processes in biological systems involving oxygen. It has been shown that cobalt(III)coordinated $\mu$-superoxo complexes react with reducing agents leading to the reduction of the $\mu$-superoxo complexes to $\mu$-peroxo complexes. Even in the case of solvated electron as the reducing agent the metal ion is not reduced in these complexes and only the $\mu$-superoxo complexes have been reduced. Investigations are undertaken to probe the redox behaviour of these complexes by pulse radiolytically produced free radicals unstable metal ions and excited state electron transfer reagents which are very powerful reducing agents. The results are summarized in figure $2 .{ }^{25,28,30}$

Direct observation of the reaction between cobalt (II)amine and molecular oxygen has been studied and the details are shown in scheme 3. Investigation with superoxide radical shows the existence of a pathway catalysed by a transition-metal complex. Although 


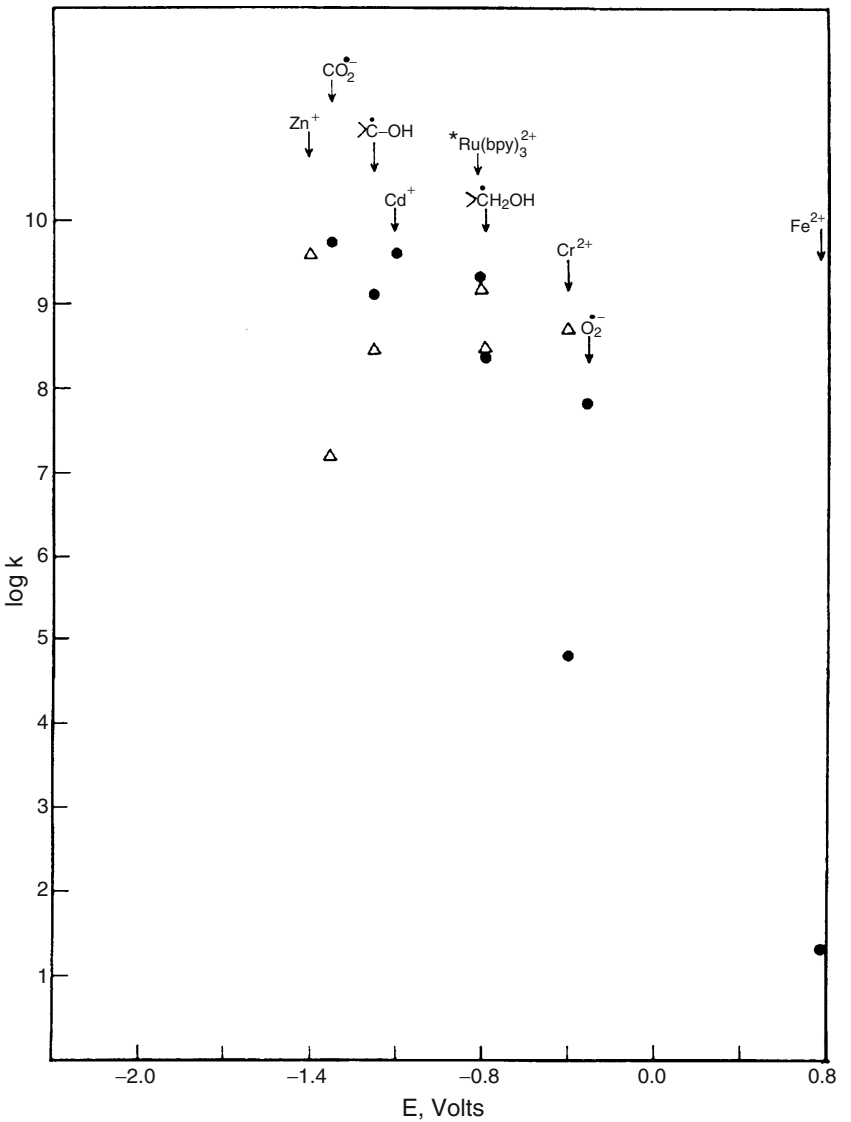

Figure 2. Plot of rate constants for the reduction of $\left[(\mathrm{en}) 2-\mathrm{Co} \mu \mathrm{O}_{2}-\mu \mathrm{NH} 2-\mathrm{Co}(\mathrm{en}) 2\right] 4 \mathrm{C}(\bullet)$ and $\left[(\mathrm{CN}) 5-\mathrm{Co} \mu \mathrm{O}_{2}-\right.$ $\mathrm{Co}(\mathrm{CN}) 5]^{5}(\Delta)$ by different reducing agents of varying redox potential. ${ }^{31}$

no known superoxide dismutase contains cobalt, this study emphasizes that in enzymatic mechanisms superoxo coordinated metal ion centers could exist and react with the superoxide ion. The reaction studied is found to be similar to the proton-catalysed dismutation reaction. ${ }^{28}$

$$
\begin{aligned}
& {\left[\mathrm{Ni}^{\mathrm{III}} \mathrm{L} \ldots \mathrm{e}_{\mathrm{aq}}^{-}\right] \rightarrow \mathrm{Ni}^{\mathrm{III}} \mathrm{L}+\mathrm{e}_{\mathrm{aq}}^{-}} \\
& \mathrm{e}_{\mathrm{aq}}^{-}+\mathrm{Ni}^{\mathrm{III}} \mathrm{L} \rightarrow \mathrm{Ni}^{\mathrm{II}} \mathrm{L} \\
& \mathrm{Ni}^{\mathrm{II}} \mathrm{L}+\mathrm{e}_{\mathrm{aq}}^{-} \rightarrow \mathrm{Ni}^{\mathrm{I}} \mathrm{L} \\
& \mathrm{Ni}^{\mathrm{III}} \mathrm{L}+\mathrm{Ni}^{\mathrm{I}} \mathrm{L} \rightarrow 2 \mathrm{Ni}^{\mathrm{II}} \mathrm{L}
\end{aligned}
$$

Scheme 4. Photolysis of nickel(II) macrocyclic complexes

\subsection{Photochemistry of nickel(II) macrocyclic complexes}

The photochemical behaviour of nickel (II) complexes on excitation in the charge-transfer to solvent bands is investigated in detail with particular reference to the study of intermediates. Investigations on the photoredox reactions of nickel(II) complexes using flash kinetic spectroscopic methods reveal details on the characteristics of the intermediates produced from the chargetransfer excited states of the nickel(II) macrocyclic metal complexes (scheme 4). ${ }^{31-33}$

Excitation of nickel(II) macrocyclic complexes using $248 \mathrm{~nm}$ laser pulse leads to the formation of solvated electron in aqueous solution. Formation of solvated electron is confirmed by observing the characteristic absorption spectrum with a maximum at $680 \mathrm{~nm}$. From the decay kinetics, bimolecular rate constants were determined for the decay of the solvated electron. Nickel (II) complexes with saturated macrocyclic ligands produce photoelectrons by biphotonic processes. Nickel(II) complex with the macrocyclic ligand ejects electron from excited states by a monophotonic process that is determined by varying the

$$
\begin{aligned}
& \mathrm{Co}(\mathrm{Am})_{4}\left(\mathrm{NO}_{2}\right)_{2} \stackrel{\mathrm{hnu}}{\longrightarrow} \mathrm{Co}(\mathrm{Am})_{4} \mathrm{NO}_{2}+\mathrm{NO}_{2} \\
& \mathrm{CO}(\mathrm{Am})_{4}\left(\mathrm{NO}_{2}\right)_{2} \quad \mathrm{O}_{2} \stackrel{\mathrm{k}_{1}}{\longrightarrow} \mathrm{Co}(\mathrm{Am})_{4} \mathrm{NO}_{2} \mathrm{O}_{2}
\end{aligned}
$$

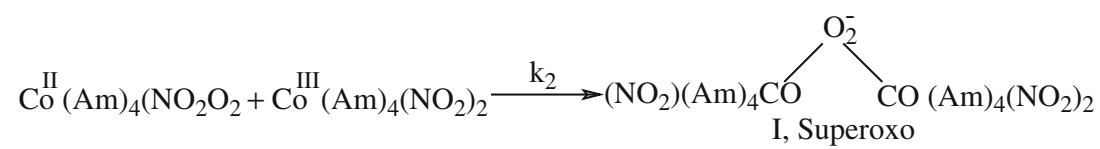

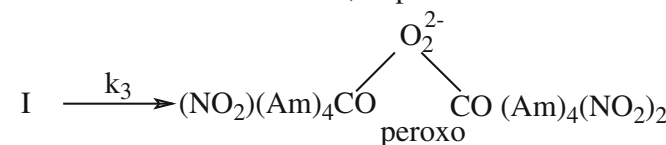

Scheme 3. Reaction between cobalt(II)ammine complex and molecular oxygen. 
excitation energy of the exciting pulse of the excimer laser (Fig. 3).
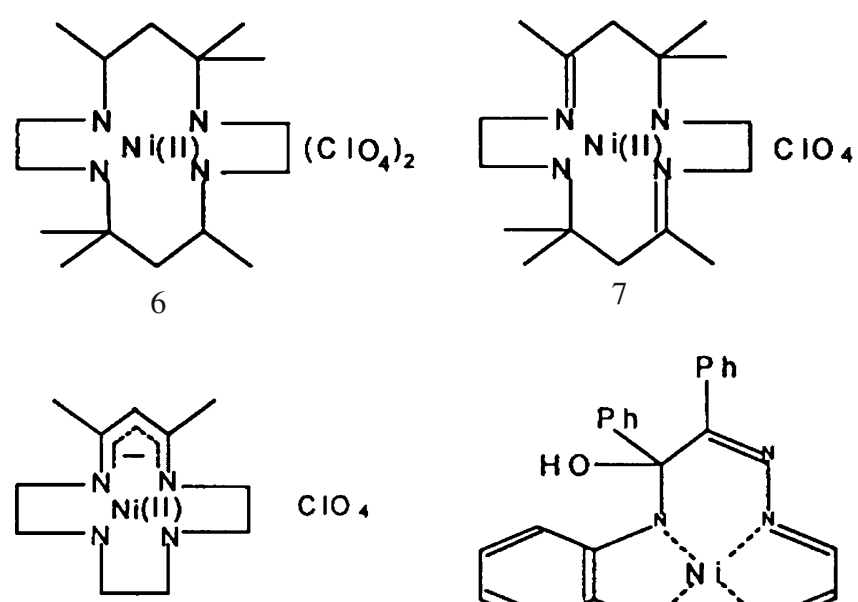

8

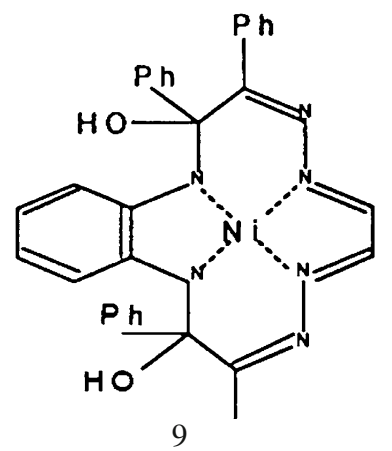

The complexes $[\mathrm{Ni}($ tet-a $)]\left(\mathrm{ClO}_{4}\right)_{2}, \mathbf{6}, \quad[\mathrm{Ni}($ htcd $)]$ $\left(\mathrm{ClO}_{4}\right)_{2}, 7$ and $[\mathrm{Ni}(\mathrm{AT})] \mathrm{ClO}_{4}, \mathbf{8}$ (where tet-a $=5,7,7,12$, 14,14-hexamethyl-1,4,8,11-tetraazacyclo tetradecane, htcd $=5,7,7,12,14,14$-hexamethyl-1,4,8,11-tetraazacyclotetradeca-4,11-diene and AT = 11,13-dimethyl-1,4, 7,10-tetraazacyclotrideca-10,12-dienato) were photolysed in the charge transfer to solvent band in nonaqueous solvents using $254 \mathrm{~nm}$ radiation. The complex [Ni(BG-opdn)], 9 (where BG-opdn = 4,9-dihydroxy3,4,9,10-tetraphenyl-6,7-benzo-1,2,5,8,11,12-hexaazacyclotetradeca-2,6,10,12,14-pentaene) was photolysed

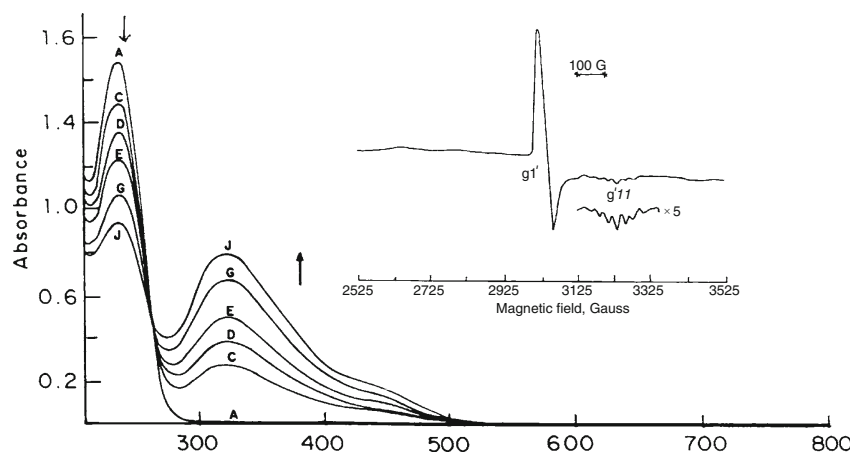

Figure 3. Steady photolysis of $\left[\mathrm{Ni}(\text { tet-a) }]^{2+}\right.$ ion in oxygensaturated acetonitrile containing $1 \mathrm{M}$ dichloromethane at $254 \mathrm{~nm}$ in a $0.1-\mathrm{cm}$ cuvette (absorbance recorded every 3 min). Inset: ESR spectra of the final solution after photolysis obtained at $77 \mathrm{~K}$. using sunlight in dichloromethane and the solid product was isolated and characterized. ${ }^{34-36}$ Flash photolysis of the complex $\mathbf{6}$ or $\mathbf{7}$ in pure acetonitrile produces transients which could be assigned to the nickel(III)carbon bonded species whereas continuous photolysis in presence of oxygen produces stable five coordinated nickel(III) complexes. Formation of nickel (III) complex is seen as a growth in absorbance at $370 \mathrm{~nm}$ in the case of complexes $\mathbf{6}$ and $\mathbf{7}$ on flash photolysis in oxygenated acetonitrile containing dichloromethane. Rate constants for the formation of nickel (III) by the reaction of alkylperoxyl radical with nickel (II) complex were determined as a function of the concentration of the complex. Continuous photolysis of complexes in acetonitrile solutions containing $1 \mathrm{M}$ dichloromethane leads to the formation of stable nickel (III)-complex that was confirmed in the case of complexes $\mathbf{6}$ and 7 by absorption and ESR spectra. In the case of complex $\mathbf{8}$ which contains a negatively charged macrocyclic ligand the oxidation of the metal centre is followed by intramolecular electron transfer to produce a nickel(II) radical centred on nitrogen which decays subsequently. In the case of complex 9 continuous photolysis using sunlight in air-equilibrated dichloromethane shows absorption spectral change and the photoproduct was isolated and characterised as nickel(II) stabilised ligand radical. Flash photolysis of 9 does not show any transient species in the microsecond time scale. Tris(bipyridyl) nickel(II) complex on laser photolysis in aqueous solution using $248 \mathrm{~nm}$ radiation produces solvated electron and oxidized bipyridine radical.

\subsection{Formation of organic product on photolysis of cobalt (III)amines with coordinated unsaturated acids}

Irradiation of itaconatopentamminecobalt(III) perchlorate complex in the ligand to metal charge transfer absorption band in aqueous solution using $254 \mathrm{~nm}$ radiation produced an oxidised ligand-free radical. The organic free radical after decarboxylation further reacts with itaconatopentamminecobalt(III) ion and also by radical dimerisation reaction to form a compound which shows broad absorption at $265 \mathrm{~nm}$ and emission at $425 \mathrm{~nm}$. The compound is identified to be a derivative of itaconic acid. The photoproduct shows two lifetimes of $1.5 \pm 0.1 \mathrm{~ns}$ and $5.5 \pm 0.5 \mathrm{~ns}$ indicating that the photoproduct decomposes at room temperature to give a second compound which is also luminescent (scheme 5). ${ }^{37}$ 

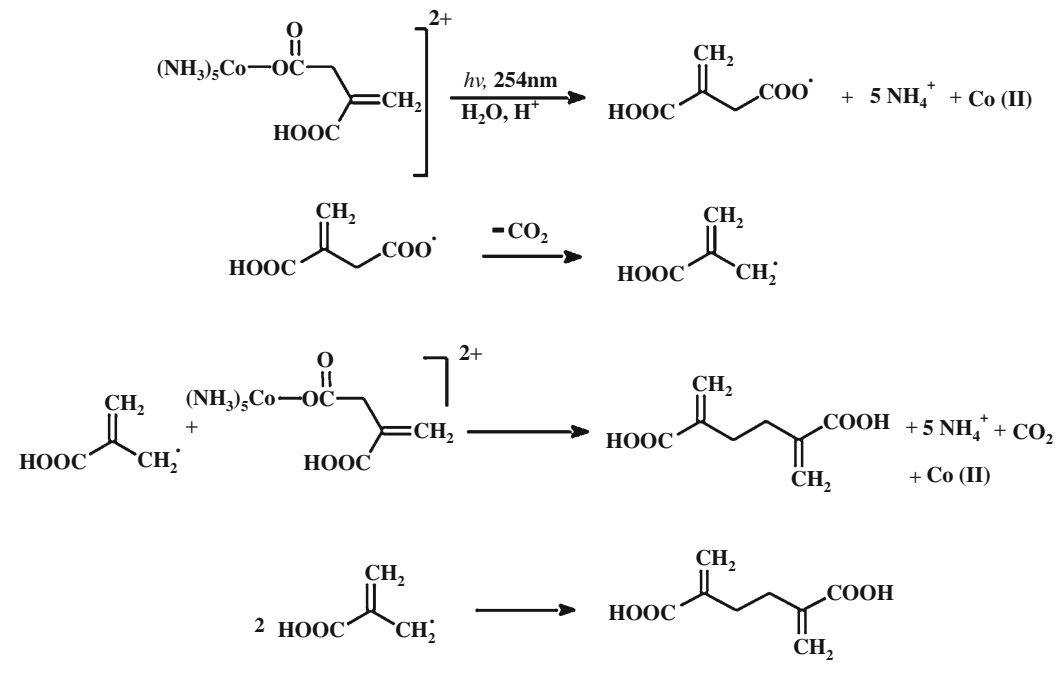

Scheme 5. Photolysis of itaconatopentammine cobalt(III) perchlorate.

\section{Photophysics of the dye molecules adsorbed onto the nanoporous silicate hosts}

In recent years photoprocesses of dyes, metal complexes and semiconductor nanoparticles encapsulated in the nanoporous silicate host materials are investigated. In these cases, the nanoporous silicate materials provide confined environment for the guest molecules, which alter the photophysics and photochemistry of guest species. Encapsulation of organic dyes into the nanoporous silicate materials has received increasing attention in recent years due to their promising application in artificial light harvesting antenna materials, optical sensors, photocatalysis, microlasers ${ }^{38-42}$ etc., Photophysics and excited state dynamics of organic dyes such as phenosafranine, proflavine, thionine and methyelene blue encapsulated into the nanoporous silicate materials have been investigated using steady state and time resolved fluorescence spectroscopic methods.

\subsection{Excited state processes of phenazine, thazine} and acridine dyes in micro and mesoporous host materials

3.1a Phenosafranine in porous silicate host materials: Phenosafranine dye in aqueous solution shows absorption maximum at $520 \mathrm{~nm}$ in the visible region and the absorption maximum is not affected significantly in different solvents; the emission maximum is observed at $595 \pm 2 \mathrm{~nm}$ depending upon the solvent polarity. The photophysical characteristics of phenosafranine adsorbed on the nanoporous silicate materials are given in table 3. The absorption spectral maximum of the dye adsorbed onto the surface of the nanoporous silicate hosts does not change significantly revealing that the absorption spectra of the dye is not sensitive to the surface polarity of the host. The fluorescence spectra of phenosafranine are found to be influenced by the host-guest interaction between the surface of the solid host and the dye molecules. The fluorescence emission maximum of the dye adsorbed on zeolite-Y, ZSM-5 and silica is blue shifted by $20 \mathrm{~nm}$ with respect

Table 3. Photophysical characteristics of phenosafranine and proflavine adsorbed on different nanoporous silicate host materials.

\begin{tabular}{|c|c|c|c|c|}
\hline Silicate host & $\begin{array}{l}\lambda_{\mathrm{abs}} \\
(\mathrm{nm})\end{array}$ & $\begin{array}{l}\lambda_{\mathrm{emi}} \\
(\mathrm{nm})\end{array}$ & $\begin{array}{l}\text { Stoke shift } \\
\Delta v\left(\mathrm{~cm}^{-1}\right)\end{array}$ & $\begin{array}{c}\tau(\mathrm{ns}) \\
\text { (\% amplitude) }\end{array}$ \\
\hline $\mathrm{Ps}^{\mathrm{a}}$ & 520 & 590 & 2281 & $0.83(100 \%)$ \\
\hline Silica & 521 & 574 & 1772 & $\begin{array}{l}0.67(14 \%) \\
1.89(86 \%)\end{array}$ \\
\hline MCM-41 & 519 & 582 & 2085 & $\begin{array}{l}0.34(38 \%) \\
1.86(62 \%)\end{array}$ \\
\hline ZSM-5 & 523 & 577 & 1789 & $\begin{array}{l}0.57(32 \%) \\
1.26(68 \%)\end{array}$ \\
\hline Zeolite-Y & 528 & 578 & 1638 & $\begin{array}{l}0.39(72 \%) \\
1.34(28 \%)\end{array}$ \\
\hline ZSM-5/Pf & 445 & 496 & 2310 & $\begin{array}{l}2.08(32 \%) \\
4.71(68 \%)\end{array}$ \\
\hline Silica/Pf & 448 & 505 & 2519 & $\begin{array}{l}1.81(49 \%) \\
4.26(51 \%)\end{array}$ \\
\hline MCM-41/Pf & 448 & 504 & 2480 & $\begin{array}{l}2.18(28 \%) \\
5.10(72 \%)\end{array}$ \\
\hline Zeolite-Y/Pf & 425 & 507 & 3805 & $\begin{array}{l}2.42(67 \%) \\
5.52(33 \%)\end{array}$ \\
\hline
\end{tabular}

${ }^{\mathrm{a}}$ In aqueous solution 
to that of the dye in aqueous solution. This observed shift in the fluorescence emission maximum of the dye in silicate hosts is comparable to that of the dye in methanol:water mixture. The fluorescence maximum of the dye adsorbed onto the external surface of zeoliteY, ZSM-5 and silica remains unaltered even though surface polarities of different silicate hosts are not the same. The photophysical behaviour of phenosafranine adsorbed onto the porous silicate materials are welldocumented earlier. ${ }^{43-45}$ Phenosafranine encapsulated into the nanochannels of MCM-41 shows emission spectral maximum comparable to that observed in aqueous solution revealing that the dye is present along with water molecules in the mesopores of MCM-41. Based on these results, we conclude that surface polarity of the nanoporous silicate host materials do not alter the photophysics of phenosafranine adsorbed on the nanoporous silicate host to a large extent.

3.1b Proflavine in porous silicate hosts: The molecular environment inside the nanoporous materials is probed by incorporating proflavine into the nanochannels of the silicate materials by impregnation method. UV-visible absorption spectra of proflavine encapsulated into the nanoporous materials with different pore sizes are shown in figure 4 . The dye encapsulated into the nanochannels of MCM-41, ZSM-5 and adsorbed on silica surface shows absorption maximum at $445 \mathrm{~nm}$ which is similar to that of the dye in aqueous solution. The dye encapsulated into the zeolite-Y shows a blue shift of $20 \mathrm{~nm}$ indicating that the cationic dye molecule is more strongly adsorbed onto the zeolite-Y as compared to that in the other nanoporous host materials. Photophysical characteristics of the dye encapsulated into the nanoporous host materials with different pore sizes are given in table 4. Proflavine encapsulated into the zeolite-Y shows a higher stokes shift compared to the other silicate hosts which is attributed to higher aluminium content in zeolite-Y framework which enhances the non-radiative decay of the excited state of the dye. The observed stokes shift of the dye is relatively less when the dye is encapsulated into the nanochannel of ZSM-5, which is attributed to confinement effect of the nanochannels of ZSM-5.

The spectral properties of proflavine in MCM-41 host are quite different when compared to that in silane modified MCM-41 and SMCM-41. Our earlier study shows that the excited state properties of proflavine are sensitive to the nature of the nanoporous environment. We have also observed a novel excited state proton transfer reaction inside the nanocavities of mesoporous
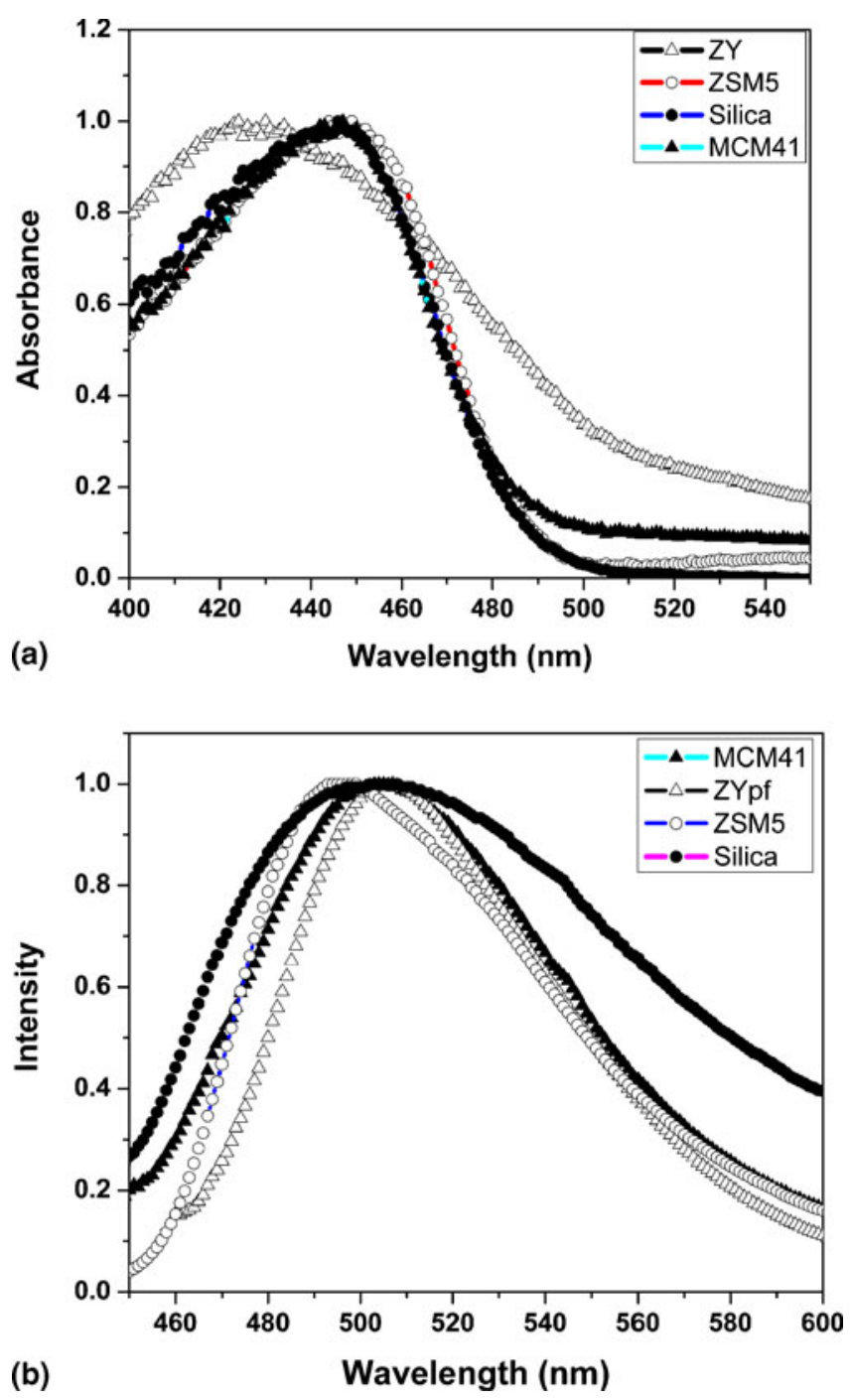

Figure 4. (a) Diffuse reflectance spectra and (b) emission spectra of proflavine encapsulated into the nanoporous host materials (excitation at $400 \mathrm{~nm}$ ).

materials as probed by the picosecond time resolved fluorescence investigated earlier. ${ }^{46}$

\section{1c Thionine and methylene blue in silicate host} materials: Photophysical properties of thionine encapsulated into the nanoporous silicate materials are given in table 4. Thionine encapsulated into the nanochannels of ZSM-5, MCM-41 and adsorbed onto the external surface of silica show maximum at $600 \mathrm{~nm}$ indicating that the dye exists in monomeric form. In the case of thionine encapsulated into the super cage of zeolite-Y, thionine is present predominantly as the dimer (scheme 6) as revealed from the characteristic intense absorption at $550 \mathrm{~nm}$ for the dimeric form of the dye. The formation of the dimeric species of thionine dye occurs in the free volume available for the 
Table 4. Photophysical properties of thionine and methylene blue encapsulated into the nanoporous silicate materials (excitation at $470 \mathrm{~nm}$ for thionine and $635 \mathrm{~nm}$ for methylene blue).

\begin{tabular}{lcclc}
\hline Sample & $\lambda_{\text {abs }}, \mathrm{nm}$ & $\lambda_{\text {emi }}, \mathrm{nm}$ & Lifetime, ns (\% amplitude) & Average lifetime, ns \\
\hline Thionine $^{\mathrm{a}}$ & 600 & 620 & 0.32 & 0.32 \\
Silica-Th & 604 & 626 & $0.27(88 \%), 2.25(12 \%)$ & 0.51 \\
MCM-41-Th & 599 & 626 & $0.16(2 \%), 0.31(98 \%)$ & 0.31 \\
ZSM-5-Th & 584 & 612 & $0.33(66 \%), 1.77(44 \%)$ & 0.99 \\
Zeolite-Y-Th & 550,602 & - & - & - \\
Methylene blue & & & 0.40 & 0.40 \\
Silica-MB & 640 & 682 & $0.33(70.99 \%), 0.78(29.01 \%)$ & 0.46 \\
MCM-41-MB & 660 & 687 & $0.32(53.58 \%), 0.69(46.42 \%)$ & 0.49 \\
ZSM-5-MB & 647 & 682 & $0.24(62.17 \%), 0.49(37.83 \%)$ & 0.33 \\
Zeolite-Y-MB & 600,658 & 675 & $0.16(57.72 \%), 0.52(42.28 \%)$ & 0.31 \\
\hline
\end{tabular}

${ }^{\text {a }}$ The lifetimes reported are within $\pm 0.05 \mathrm{~ns}$

guest within the super cage of zeolite-Y. Super cage of zeolite-Y is approximately spherical in nature with a diameter of $13 \AA$ and a free volume of $827 \AA^{3}$ that is large enough to accommodate $\mathrm{H}$-aggregated thionine molecules. ZSM-5 consists of two intersecting sets of tubular channels $(\approx 0.54 \mathrm{~nm}$ and $0.56 \mathrm{~nm}$ in diameter) defined by 10 -membered ring of $\mathrm{TO}_{4}(\mathrm{~T}=\mathrm{Si}$ or $\mathrm{Al}$ ) tetrahedra. Thus, three possible adsorption sites in ZSM-5 are straight channels, channel intersection and sinusoidal channels. Among these three sites of the channels, channel intersection has large free space for guest molecules having the diameter of $8.7 \AA$. Assuming near spherical cavity, this space can not accommodate $\mathrm{H}$-aggregates since more spherical free volume is needed to include stacked thionine molecules (the stacked dimer is approximately of the size $15 \AA \times$ $7.2 \AA \times 8 \AA$ ). The host material MCM-41 has tubular channel with $\approx 4 \mathrm{~nm}$ in diameter and has larger space to accommodate the dimer. However, no dimer is present in the nanochannels of MCM-41 as indicated in the absorption spectrum. In this case the polarity of the host plays an important role in preventing the formation of the dimer. Thionine adsorbed on the silica at the external surface is present only as monomer, since no peak at $550 \mathrm{~nm}$ is observed in the absorption spectrum.

Thionine encapsulated into the ZSM-5 channel shows absorption maximum at $582 \mathrm{~nm}$ blue shifted by around $20 \mathrm{~nm}$ as compared to the dye in aqueous solution as shown in table 4 . The $\pi-\pi *$ transitions of the aromatic molecules is shifted to the red when the
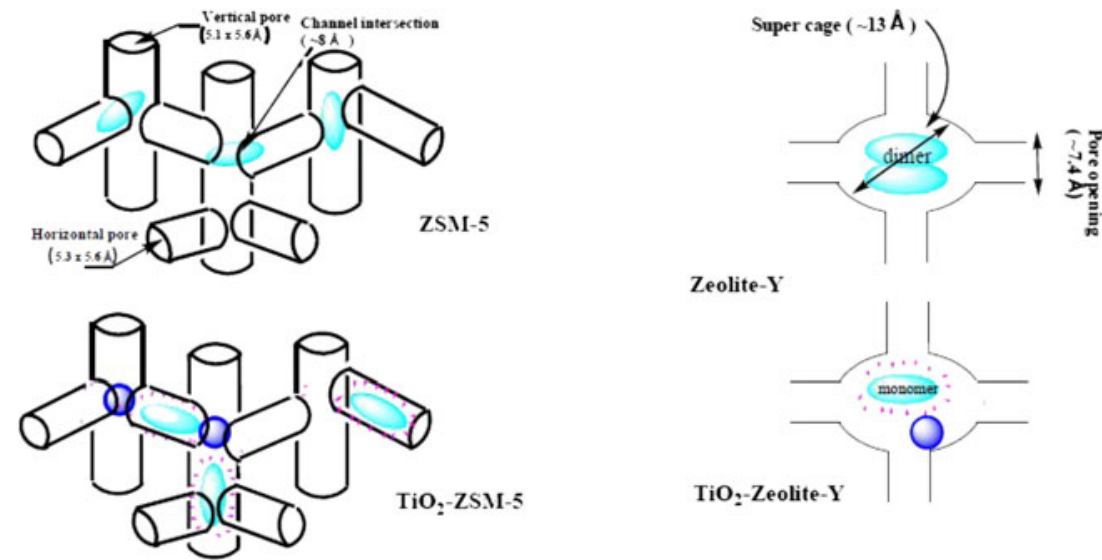

Zeolite-Y
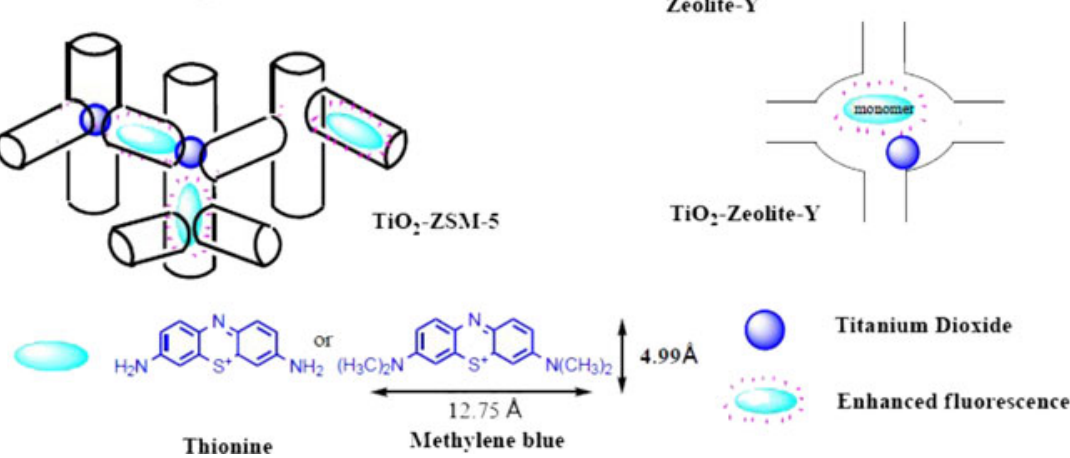

Scheme 6. Thionine and methylene blue into the nanoporous silicate materials. 
molecule is more planar or with increasing aromatic character. ${ }^{47}$ Accordingly, in the thionine molecule the lone electron pair on the nitrogen becomes part of the aromatic system. Thionine dye encapsulation in ZSM-5 channel results in the terminal nitrogen atom tilting out of the aromatic plane due to steric hindrance, causing a blue shift in the absorption spectrum. Similar blue shift was reported ${ }^{46}$ in the case of methylene blue present in the interlameller surface due to the change in the orientation of the molecular plane. Such a blue shift is not observed for thionine in the hosts MCM-41, zeolite-Y and silica due to the presence of larger free space in the host cavity at the external surface.

The dye thionine encapsulated into the MCM-41 and adsorbed onto the external surface of silica shows a red shift in the emission maximum at $626 \mathrm{~nm}$ as compared to that of the dye in aqueous solution. The observed red shift in the emission maximum is due to the interactions of the guest with $\mathrm{OH}$ groups of the silicate framework. Fluorescence emission is found to be absent for thionine encapsulated into zeolites-Y cavities due to the presence of the aggregated thionine in the cavity. In the case of thionine encapsulated into the channels of ZSM-5, a weak emission is indicated at $612 \mathrm{~nm}$. The observed blue shift in the emission maximum is suggested to be due to the confinement effect of the channel. The presence of aluminium atom, water molecules and confinement effect of nanoporous silicate host play an important role on the photophysics of organic dyes; size of organic chromophores is also important in the preparation of host-guest antenna materials.

\subsection{Photosensitisation of semiconductor nanoparticles adsorbed onto nanoporous hosts}

3.2a Photosensitization of $\mathrm{TiO}_{2}$ and $\mathrm{ZnO}$ by phenosafranine and proflavine excited states: Photosensitization of titanium dioxide nanoparticles encapsulated in the supercages and anchored on the external surface of the nanoporous silicate host by the visible light excited dye molecules has been investigated using steady state and time resolved fluorescence and absorption techniques. Titanium dioxide loaded nanoporous silicate hosts at the external surface and at the interior of the host surface are found to show different characteristics in the sensitization process.

With increasing $\mathrm{TiO}_{2}$ loading into the nanochannels and nanocavities of silicate host shows decrease in fluorescence intensity of the $\mathrm{PS}^{+}$dye. The fluorescence lifetime of phenosafranine (figure 5) encapsulated into
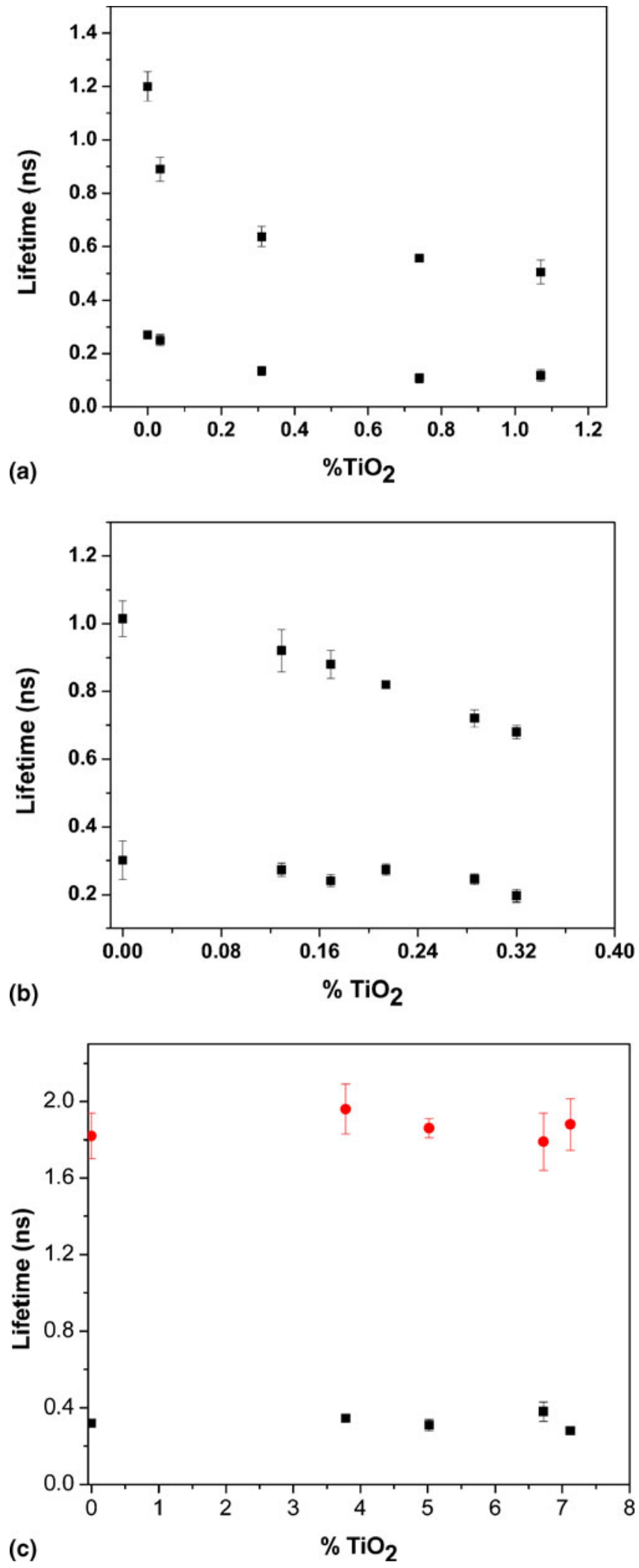

Figure 5. Plot of fluorescence lifetime of phenosafranine adsorbed onto the (a) zeolite-Y, (b) ZSM-5 and (c) MCM41 versus titanium dioxide loading. 
the $\mathrm{TiO}_{2}$ loaded MCM-41 channel shows no significant change. Fluorescence intensity was decreased in presence of $\mathrm{TiO}_{2}$ in the steady state experiment indicating that the quenching processes are static in nature since both the dye and semiconductor nanoparticles are encapsulated in the nanochannels. In the case of the dye adsorbed on the zeolite-Y and ZSM-5, the fluorescence lifetime (figure 5) decreases with increase in concentration of titanium dioxide encapsulated in the nanochannels or nanocavity of the zeolite host. Decrease in fluorescence lifetime of the dye with increasing $\mathrm{TiO}_{2}$ loading is suggested to be due to the interaction of the dye in excited state with the semiconductor nanoparticles through the zeolite network. The photosensitization of titanium dioxide nanoparticle encapsulated into the silicate host by phenosafranine was confirmed using picosecond pump-probe experiments. ${ }^{48}$

The operative mechanism of quenching is static in these cases for the dye which sensitizes the titanium dioxide nanoparticles at the external surface of zeoliteY. It is known that interfacial electron injection from the excited state of the adsorbed dye to the semiconductor occurs within femtosecond time scale and the quenching which occurs within the time resolution of the instrument, which is of the order of a few picoseconds could not be seen in the pump-probe experiments. The observed emission is only from those molecules, which do not interact with titanium dioxide directly, while the excited states of the dye which interact in contact with titanium dioxide are quenched. Interaction of semiconductor nanoparticles with the dye molecule alters the ground and excited state of the adsorbed dye molecules. In general, the interaction of the sensitizer with the semiconductor particles at the host surface leads to change in ground and excited states of the sensitizer. This observed behaviour shows that the emission of the dyes in titanium dioxide loaded MCM-41 is from the molecules which are not interacting with the titanium dioxide. The electron injection rate constant can be calculated from the decrease in lifetime of the dye in presence of semiconductor. Due to the multiexponential fluorescence decay curve, we were not able to calculate the rate constant for electron injection.

Diffuse reflectance laser flash photolysis studies of phenosafranine encapsulated in MCM-41 nanocomposites show absorption bands with maxima at around 605, 660 and $700 \mathrm{~nm}$ (figure 6) for the transients which are attributed to the protonated form of the triplet excited state $\left(3 \mathrm{PSH}^{2+}\right)$. Such type of transient absorption spectra of phenosafranine is not observed in the presence of semiconductor nanoparicle inside the nanochannels of MCM-41. The mechanism of photosensitization is sug-
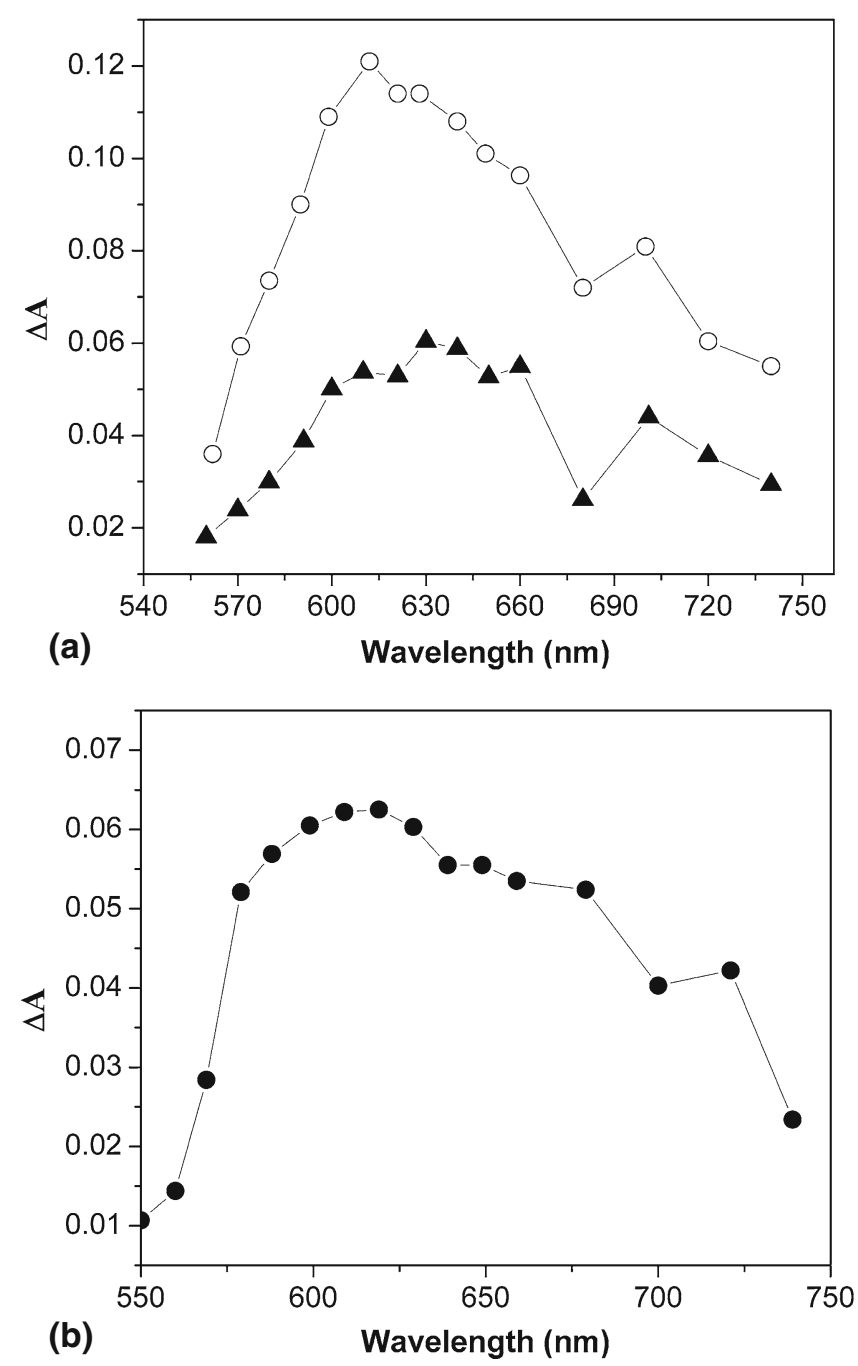

Figure 6. (a) Diffuse reflectance transient absorption spectrum of phenosafranine encapsulated in MCM-41. (b) Diffuse reflectance transient absorption spectrum of phenosafranine encapsulated in AlMCM-41. ${ }^{45}$

gested to be of charge transfer type which occurs at time scale in the sub-pico second domain.

In order to further understand the photosensitization of phenafranine in the presence of semiconductor nanoparticles, the photochemistry of phenosafranine adsorbed on nanochannels and nanocavity of silicate host is investigated in the absence and presence of semiconductor nanoparticles encapsulated within porous silicate host using picosecond pump-probe techniques. Phenosafranine adsorbed on the porous silicate host shows a broad transient absorption in the picosecond pump-probe experiment, which is due to the formation of trapped electron, cation radical and triplet state of the dye. Phenosafranine adsorbed on $\mathrm{TiO}_{2}$ loaded silicate 
host shows absorption maximum of the transient corresponding to the cation radical and triplet state, which confirms the photo-induced electron transfer from surface adsorbed phenosafranine in the excited state to semiconductor nanoparticles within the porous silicate host. The porous silicate host provides ultrafast charge separation and also prevents the back electron transfer from semiconductor nanoparticles to photooxidized products of the dye.

Proflavine and titanium dioxide nanoparticles encapsulated into the nanoporous materials do not show significant change in the absorption spectral maximum. The fluorescence intensity of proflavine decreases with increase in the loading of titanium dioxide nanoparticles in nanoporous silicate hosts (figure 7a). The
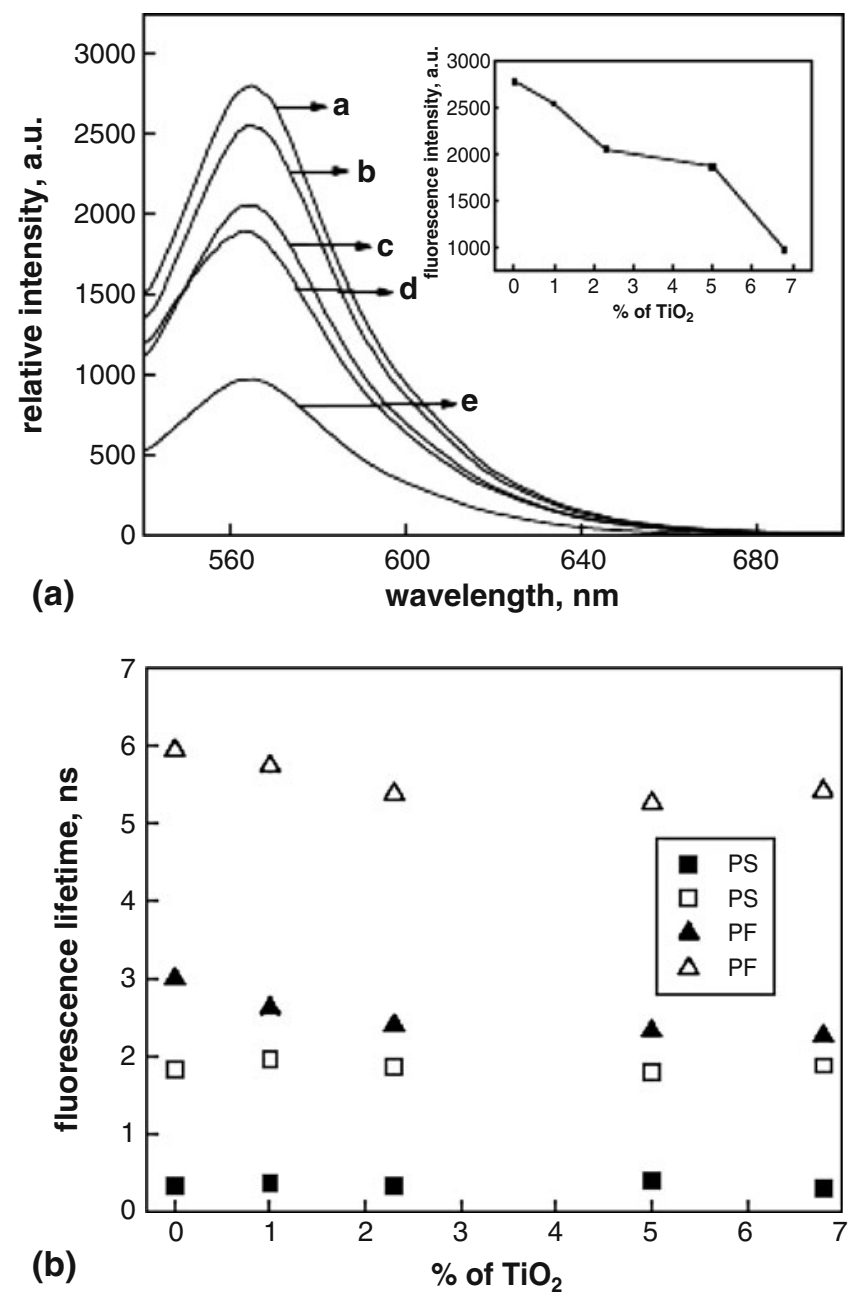

Figure 7. (a) Fluorescence spectra of proflavine encapsulated in $\mathrm{TiO}_{2}-\mathrm{MCM}-41$ (a: $0 \% \mathrm{TiO}_{2}$, b: $1 \% \mathrm{TiO}_{2}$, c: $2.3 \%$ $\mathrm{TiO}_{2}$, d: $5 \% \mathrm{TiO}_{2}$, e: $6.8 \% \mathrm{TiO}_{2}$; inset: plot of fluorescence intensity at $502 \mathrm{~nm}$ versus concentration of $\mathrm{TiO}_{2}$ ) and (b) Plot of fluorescence lifetime of phenosafranine and proflavine versus concentration of titanium dioxide. ${ }^{45}$ fluorescence lifetime of proflavine in the voids of nanoporous host do not show significant change with increase in the titanium dioxide loading as shown in figure $7 \mathrm{~b}$. The relative contribution of the two fluorescence lifetime of proflavine remains unchanged with increasing loading of titanium dioxide in the host materials. The small variation observed in the amplitude for the shorter lifetime component may be due to change in the polarity of the particular host. Similar observation has been reported earlier for $\mathrm{Ru}(\mathrm{bpy})_{3}^{2+}$ complex ${ }^{49}$ doped in MCM-41 containing titanium dioxide nanoparticles and also proflavine encapsulated into the nanochannels of zeolite-Y with titanium dioxide. ${ }^{45}$ Since $\mathrm{TiO}_{2}$ is known to quench the excited state of proflavine, the observed fluorescence emission of the dye attributed to the proflavine molecules that are not in direct contact with titanium dioxide. Steady state experiments also reveal that proflavine molecules located near the titanium dioxide in zeolite-Y host do not emit; fluorescence emission intensity of the dye in the host gradually decreases while the fluorescence lifetime of the excited state of the dye in host materials remains constant with increase in the $\mathrm{TiO}_{2}$ loading. These observations are consistent with static quenching mechanism of proflavine excited state by $\mathrm{TiO}_{2}$ due to restricted movement of both dye and semiconductor in zeolite$\mathrm{Y}$ host. In the case of the dye encapsulated into the nanochannels of ZSM-5 with various loading of titanium dioxide, there is no change in the fluorescence lifetime even though observed decrease in the fluorescence emission intensity with red shift in the emission maximum.

3.2b Influence of $\mathrm{TiO}_{2}$ on the aggregation of thionine and methylene blue in porous silicate hosts: Thionine and methylene blue dyes are incorporated in nanoporous silicate hosts; MCM-41, ZSM-5, zeolite$\mathrm{Y}$ and adsorbed on silica. It is observed that the protonation and aggregation of the dyes depend strongly on the size and acidity of the nanochannels and nanocavities of silicate hosts. Aggregation of thionine is controlled by changing the titanium dioxide loading in zeoliteY. Protonation of the dye occurs in the case of titanium dioxide loaded ZSM-5 due to change in acidity of the host in the presence of titanium dioxide. Thionine in $\mathrm{TiO}_{2}$ loaded ZSM-5 undergoes excited state interconversion into isomers that is confirmed by picosecond and femtosecond fluorescence studies reported earlier. ${ }^{40}$ In the femtosecond up-conversion technique it has been observed that the initially excited thionine relaxes to a lower excited state in about 2 ps 

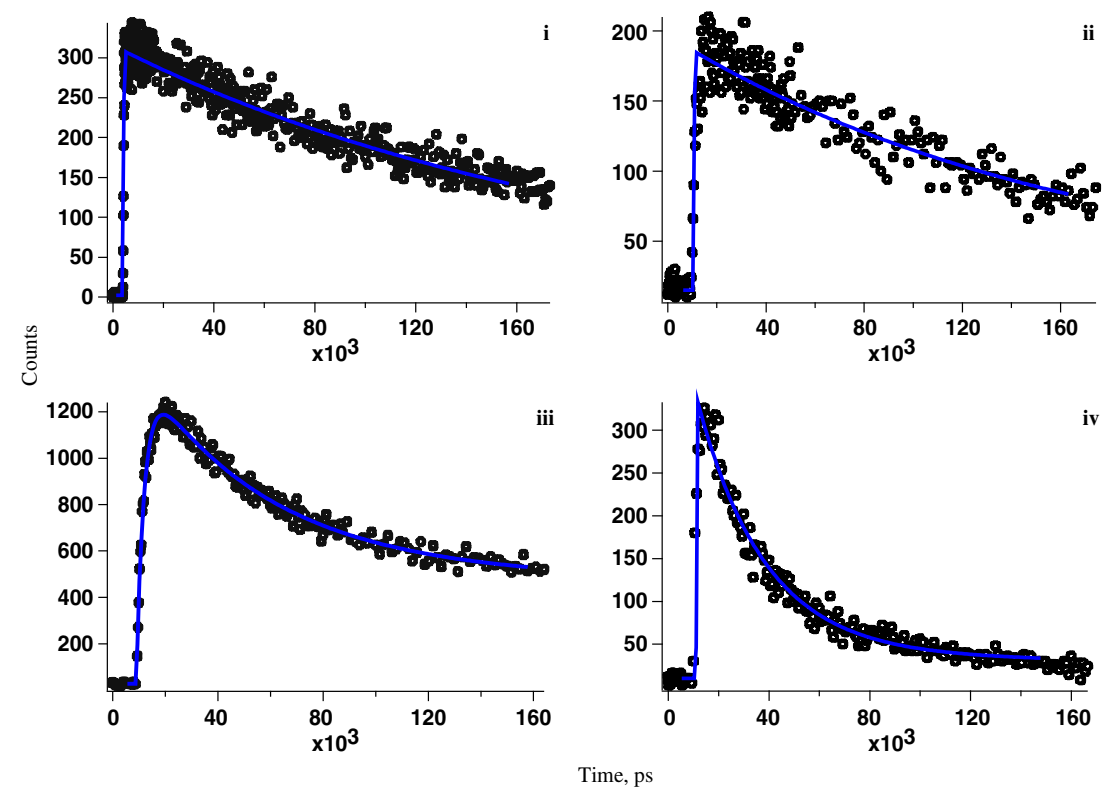

Figure 8. Femtosecond florescence decay of thionine in (i) aqueous solution at $620 \mathrm{~nm}$, (ii) MCM-41 at $630 \mathrm{~nm}$, (iii) ZSM-5 at $630 \mathrm{~nm}$ and (iv) ZSM-5 at $585 \mathrm{~nm}$ (excitation at $445 \mathrm{~nm}) .{ }^{41}$

(figure 8). These two excited state species of the dye show emission maxima at $612 \mathrm{~nm}$ and $625 \mathrm{~nm}$. The thionine dye encapsulated in MCM-41 host does not show this behaviour. Methylene blue encapsulated in MCM-41 and ZSM-5 loaded with $\mathrm{TiO}_{2}$ shows charge transfer process from the excited state of the dye to the semiconductor as revealed from the steady state and time resolved emission spectral studies.

\section{Excited state redox processes of organic dyes covalently bound to synthetic polymers: Effect of polymeric microheterogeneous environment in aqueous solution}

Polymers, especially polyelectrolytes are extensively used as a medium to carry out the reactions involving charge transfer. The combination of macromolecular and electrolytic nature of polyelectrolytes restricts the diffusion of the products and conducts the charge over the distance. In particular, during the photochemical charge separation, the rate of the charge recombination is reduced by the macromolecular environment and acts as charge carrier. With these advantages, the electrochemistry, photochemistry and the photoelectrochemistry of dyes and metal complexes covalently attached to the polyelectrolytes have been studied.

\subsection{Photovoltaic conversion at the electrodes in macromolecular thionine films}

The photo-oxidation of ferrous ion in solution by the excited state of thionine dye on visible light absorption is known since a long time. ${ }^{50}$ The photoproducts recombine in dark to generate the reactants back in solution. The photogalvanic potentials generated by this cyclic process is examined for solar energy conversion. ${ }^{51}$ However, the efficiency of the conversion is very low due to the energy wasting back reactions in solution and due to the restriction imposed on the dissolution of the dye in solution. It was shown that these limitations can be overcome if thick films $(\sim 10 \mu \mathrm{m})$ of thionine condensed with macromolecules are coated on to

$$
\begin{aligned}
& \mathrm{P}-\mathrm{TH}^{+}-\stackrel{h v}{\longrightarrow} * \mathrm{P}-\mathrm{TH}^{+} \\
& * \mathrm{P}-\mathrm{TH}^{+}+\mathrm{Fe}^{\mathrm{II}}-\stackrel{H^{+}}{\rightarrow} \quad\left[\mathrm{P}-\mathrm{TH}_{2}-\mathrm{Fe}\right]^{4+} \\
& {\left[\mathrm{P}-\mathrm{TH}_{2}-\mathrm{Fe}\right]^{4+}+\mathrm{e}^{-}-\rightarrow \mathrm{P}-\mathrm{TH}_{2}^{\mathrm{g}+}+\mathrm{Fe}^{\mathrm{II}}(\text { cathode) }} \\
& \mathrm{Fe}^{\mathrm{II}}-\rightarrow \mathrm{Fe}^{\mathrm{III}}+\mathrm{e}^{-} \text {(anode) } \\
& \mathrm{P}-\mathrm{TH}_{2}^{\mathrm{g}^{+}}-\mathrm{Fe}^{\mathrm{III}}-\rightarrow \mathrm{P}-\mathrm{TH}^{+}+\mathrm{Fe}^{\mathrm{II}}+\mathrm{H}^{+}
\end{aligned}
$$

Scheme 7. Photovoltaic conversion in macromolecular thionine films. 


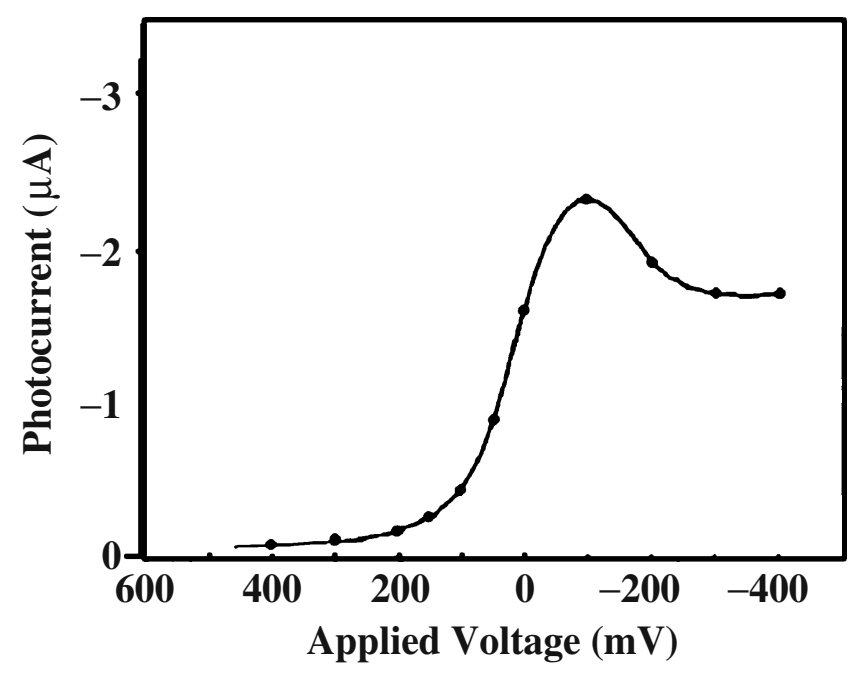

Figure 9. Photocurrent plotted against applied voltage across the working electrode-reference electrode for polymer-thionine coated electrode. ${ }^{50}$

inert electrodes. ${ }^{50,52,53}$ The electrodic reactions resulting in the generation of photocurrent upon illumination is shown in scheme 7 and the $\mathrm{i}-\mathrm{v}$ diagram at various applied potential is shown in figure 9 .

Photoelectrochemical studies carried out with macromolecular phenosafranine dye indicate different behaviour depending upon the nature of macromolecule with which the dye is covalently bound. ${ }^{54}$ In the case of an electrode coated with a film of poly(acrylamidomethyl phenosafranine-co-methylolacrylamide) cathodic behaviour was observed with reference to an inert electrode. Electrodes coated with a film of poly (acrylamide methyl phenosafranine-co-methylolacrylamide-covinylpyridine) exhibited anodic polarity. A watersplitting regenerative cell was shown to operate using the polymeric phenosafranine-coated electrodes. ${ }^{55-57}$ Modification of the electrode by coating with poly (acrylamido glycolic acid)-thionine, $\mathrm{P}(\mathrm{AGA})-\mathrm{TH}^{+}$, improves the efficiency of the photogalvanic cell. In the case of $\mathrm{P}(\mathrm{AGA})-\mathrm{TH}^{+}$, in homogeneous solution and $\mathrm{P}(\mathrm{AGA})-\mathrm{TH}^{+}$coated electrodes, in addition to the photo-induced current, a polarity change in the photopotential, and hence a change in current flow, is noted. The nature of the polymer backbone is suggested to be responsible for the novel observation. ${ }^{52,54}$

Photoelectrochemical cells were constructed using polymer-dye-coated electrodes with electropolymerized zinc(II) 5-(4'.hydroxy)phenyl- 10,15,20triphenylporphine and anthraquinone-2-(1-pyrrole) monomers, and the response to light was investigated in air-equilibrated and under deaerated conditions. ${ }^{58-61}$ A mechanism is proposed for the reaction of molecular oxygen at the electrode with the photogenerated species based on the recorded photopotential, photocurrent, action spectra and the $\mathrm{i}-\mathrm{V}$ curves. The migration of the photogenerated charge carriers in different modified electrodes and the role of quinone dissolved in solution are discussed. ${ }^{62}$

\subsection{Cyclic voltammetric studies of dyes bound to macromolecules in aqueous solution}

Thionine and phenosafranine dyes are condensed with the polymers poly ( $N$-methylolacrylamide), poly ( $N$-methylolacrylamide-co-acrylic acid) and poly ( $N-$ methylolacrylamide-co-vinylpyridine) and the electrochemical properties of the polymer bound dyes are investigated by cyclic voltammetry. ${ }^{63,64}$ In the presence of the polymer backbone the photoreaction of the dye at the electrode is found to be quasi reversible. The mechanism of the electrodic reaction for the polymer bound dye is suggested to be E-E type. Increasing the number of dye molecules in the polymer chain leads to the aggregation of dye molecules in aqueous solution, which results in the shift of the peak to negative potential. Nature of the polymer backbone and (a)

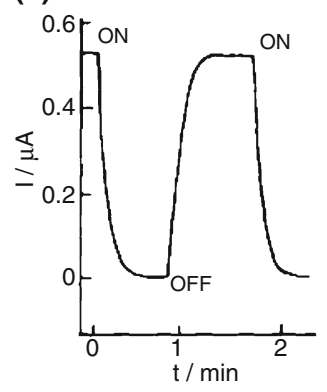

(b)

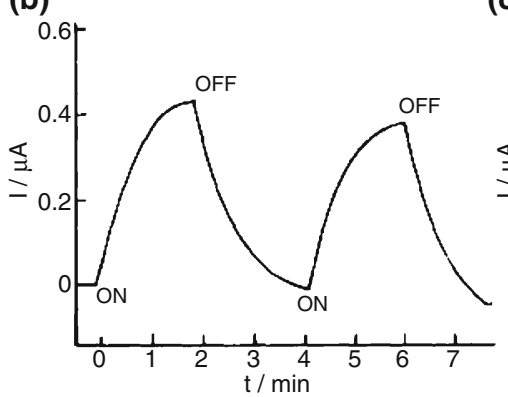

(c)

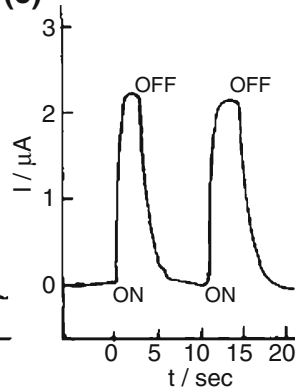

Figure 10. Photocurrent for iron-thionine system (a), iron- $\mathrm{P}(\mathrm{AGA})-\mathrm{TH}{ }^{+}$in homogeneous solution (b) and iron-P(AGA)- $\mathrm{TH}^{+}{ }_{-}^{+}$coated electrode (c) for 'light on' and 'light off' conditions. ${ }^{55}$ 
the electrostatic charge present in the chain markedly affect the redox potentials for the electron transfer processes. Cyclic-voltammetry of phenosafranine bound to the polymer adsorbed at the carbon electrode show subsequent two-electron redox reactions of the dye. Cyclic voltametric behaviour of electrodes coated with macromolecular bound ruthenium complexes was investigated. Electrodic behaviour of bis(bipyridine)-dichlororuthenium(II) condensed with poly(vinylpyridine) and its copolymers with methylolacrylamide (figure 10) was investigated as films coated on platinum and ITO plates. Macromolecular ruthenium complexes containing covalently bound thionine dye was prepared and the electrochemical behaviour was investigated. Number of ruthenium complex centres bound to the macromolecular chain has been varied and the redox behaviour of the metal complex in the presence macromolecular chain has been studied. ${ }^{65}$

\subsection{Photochemistry of macromolecular bound dyes and metal complexes}

The macromolecular ruthenium (II) complexes which are soluble in water were synthesized and the absorption and emission properties of the polymers were investigated in aqueous solution. Photolysis of the complex in aqueous solution leads to photoaquation reactions with the release of coordinated pyridine from the coordination compound bound to the polymer. Quatum yields for the redox decomposition of cis-[Co(en $\left.)_{2}(\mathrm{PVP}) \mathrm{X}\right]^{2+}$ (en-ethylenediamine; pvp-poly(vinylpyridine), $\mathrm{X}-\mathrm{Cl}$ or $\mathrm{Br}\}$ ions are significantly affected by the presence of the macromolecular ligand. ${ }^{66}$ In the case of monomeric complex, cis-[Ru(bpy $\left.)_{2}(\mathrm{py})_{2}\right] \mathrm{Cl}_{2}$, photolysis in water in presence of $\mathrm{Cl}^{-}$ions produces only the substitution of the pyridine by water whereas in the polymeric complexes, $\left.\left[\mathrm{Ru}(\mathrm{bpy})_{2} \text { (MAAM-co-VP }\right)_{2}\right] \mathrm{Cl}_{2}$ and $\left[\mathrm{Ru}(\mathrm{bpy})_{2}\left(\mathrm{AM}-\mathrm{co}-\mathrm{VP}_{2}\right] \mathrm{Cl}_{2}\right.$ photolysis in the presence of chloride produces $\left[\mathrm{Ru}(\mathrm{bpy})_{2}(\mathrm{MAAM}-\mathrm{co}-\mathrm{VP}) \mathrm{Cl}\right] \mathrm{Cl}$ and $\left[\mathrm{Ru}(\mathrm{bpy})_{2}(\mathrm{AM}-\mathrm{co}-\mathrm{VP}) \mathrm{Cl}\right] \mathrm{Cl}$, respectively. ${ }^{67}$

Thermal substitution reactions of macromolecular chromium(III) complexes in basic solutions lead to the replacement of the polypyridyl ligand by hydroxide ion while in strong acidic solutions the polymer complexes precipitate out. ${ }^{68}$ The photochemical reactions are qualitatively similar to that of the thermal reactions and the quantum yields are dependent on the $\mathrm{pH}$ of the medium. Further, lower quantum yields were observed for the aquation of the polymer complexes in comparison with the monomeric chromium(III) complexes and the results are discussed in terms of the effect of the polymer environment. Flash photolysis of the complexes results in the formation of transients with maxima at 480 and $580 \mathrm{~nm}$ and the transients were suggested to be the alkyl-chromium complexes.

The observed fluorescence from the excited state of thionine bound to the polymer is quenched by ferrous and ferric ions in aqueous solutions, with a diffusionally limited bimolecular quenching constants. ${ }^{69,70}$ Flash photolysis of the polymer-thionine complexes in the presence of ferrous ions shows adduct formation between the polymer-bound thionines and ferrous ion; the polymeric semithionine dissociated from this complex undergoes disproportionation reaction and the rate constant for the disproportionation process of the polymer-semithionine radical is two orders of magnitude lower than that for the monomeric semithionine in aqueous solution. The disproportionation reaction is found to occur between the semithionines bound to the same polymer chain.

Thionine and rutheniurn(II) bipyridyl complex were attached as pendants to poly(methylolacrylamide-covmylpyridine) and the interaction between the two dyes was investigated. The excited state relaxation of thionine mediated by the macromolecular chain was observed. ${ }^{65,71}$ When both thionine and ruthenium(II) complex are bound to the same macromolecule following observations are noted: (i) a shift of the absorption and emission spectral maxima of thionine and not of the ruthenium(II) complex (table 5); (ii) the lifetime of the polymer-bound ruthenium $(\mathrm{H})$ complex is decreased by $50 \%$ compared to the macromolecular ruthenium (II) complex in the absence of thionine; and (iii) lack of aggregation between the thionine centres.

Table 5. Characteristics of the polymer-bound thionine and ruthenium(II) complex.

\begin{tabular}{|c|c|c|c|c|}
\hline Sample & $\mathrm{m} / \mathrm{d}$ & $\lambda_{\text {abs }}(\mathrm{nm})$ & $\lambda_{\mathrm{cmi}}(\mathrm{nm})$ & $\tau(\mathrm{ns})$ \\
\hline $\mathrm{P}\left(\mathrm{VP}-\mathrm{co}-\mathrm{AmTH}^{+}\right.$-co-MAAM $)$ & $70 \pm 20$ & 585,615 & 640 & - \\
\hline$\left[\mathrm{Ru}(\mathrm{bpy})_{2}\left(\mathrm{VP}-\mathrm{co}-\mathrm{AmTH}^{+} \text {-co-MAAM) }\right]^{2+}\right.$ & $70 \pm 20$ & 460,635 & 660 & $20 \pm 2$ \\
\hline$\left[\mathrm{Ru}(\mathrm{bpy})_{2}(\mathrm{VP}-\mathrm{co}-\mathrm{MAAM})\right]^{2+}$ & - & 460 & 610 & $34 \pm 2$ \\
\hline
\end{tabular}


Protoporphyrin IX and thionine were covalently linked to the macromolecules poly(acrylic acid) and poly(methylolacrylamide) and the fluorescence lifetime of the bound dyes were measured by time-resolved methods. The decay curves were fitted well to biexponential kinetics, indicating that the chromophore is located in two different environments of the macromolecule. It was inferred from the fluorescence lifetime measurements and emission intensity profile that the excited state of the porphyrin is quenched by thionine bound to the same macromolecular chain. It is suggested that the quenching process is mediated by the macromolecular random coil which appears to be more efficient when the polymer chain is poly (methylolacrylamide). Stem-Volmer plot analysis of the quenching process suggests that it follows a static mechanism when the polymer chain contains acrylamide groups. ${ }^{72,73}$

\section{Fluorescence studies on the dynamics \\ of polyelectrolytes covalently bound with fluorophores in aqueous solution}

Fluorescence method is a powerful tool to study the dynamics of the macromolecules in solutions and in melts. Conformational transitions of polyelectrolytes induced by changes in the degree of ionization of the carboxylic groups of the polyelectrolytes have been investigated by different techniques. ${ }^{74}$ Fluorescence techniques are useful to study the kinetics of the expansion of poly(carboxylic acid) induced by $\mathrm{pH}$ jump methods. ${ }^{75-78}$ The nature of expansion of polymethacrylic acid chain in aqueous solution induced by the ionization of carboxylic acid is not fully understood though extensive investigations have been carried out. ${ }^{79}$ The solvent and structural environment of the polyelectrolyte changes the photophysical properties of the covalently bound fluorophores present in the macromolecule. ${ }^{80,81}$ The characteristics of the solvent environment around the poly(carboxylic acids) using covalently bound fluorophores thionine and phenosafranine on the macromolecular dynamics are studied by time resolved measurements.

\subsection{Steady state fluorescence studies of the polyelectrolytes with bound fluorophores}

The absorbance of phenosafranine and thionine bound to PMAA increases with increasing the $\mathrm{pH}$ from 2.6 to 4.0 and starts to decrease when the $\mathrm{pH}$ increases
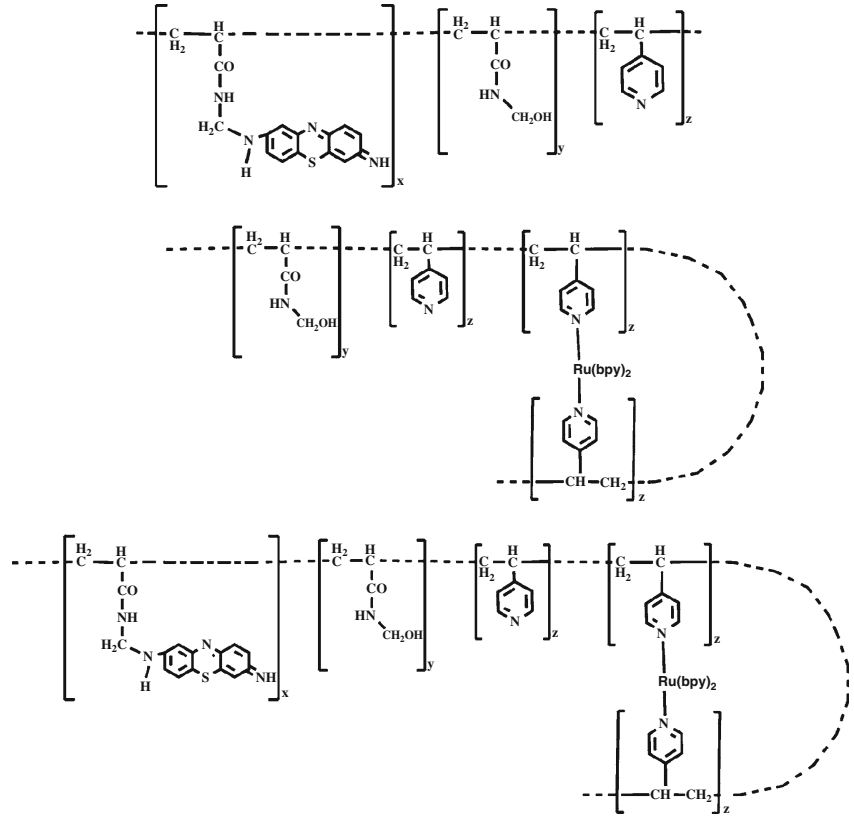

Figure 11. Structures of $\mathrm{P}\left(\mathrm{VP}-\mathrm{co}-\mathrm{AmTH}^{+}\right.$-coMAAM $), \quad\left[\mathrm{Ru}(\mathrm{bpy})_{2}\left(\mathrm{VP}-\mathrm{co}-\mathrm{AmTH}^{+} \text {-co-MAAM }\right)_{2}\right]^{2+}$ and $\left[\mathrm{Ru}(\mathrm{bpy})_{2}(\mathrm{VP}-\mathrm{co}-\mathrm{MAAM})_{2}\right]^{2+}$.

above 5.0 without much shift in the maxima. ${ }^{82}$ Absorption spectral changes observed at different $\mathrm{pH}$ for the cationic dye auramine-O bound PMAA follow similar trend. ${ }^{83,84}$ The absorbance of the poly(MAA-Ph) and poly(MAA-Th) is maximum at $\mathrm{pH} 4.0$ due to the presence of fluorophores in the hydrophobic core of the poly(methacrylic acid). The insignificant change in the absorbance of PAA bound dyes is explained to be due to the absence of hydrophobic methyl group in PAA. ${ }^{85}$

The emission spectra of $\mathrm{P}(\mathrm{MAA}-\mathrm{Ph})$ and $\mathrm{P}(\mathrm{MAA}-$ $\mathrm{Th})$ at different $\mathrm{pH}$ are shown in figure 11 . The cationic dye binds with the polycarboxylate anionic sites due to the electrostatic attraction in the partially ionized state of poly(methacrylic acid) at $\mathrm{pH} \approx 4.0{ }^{86}$ As a consequence, the polymer chain in the vicinity of fluorophore displaces water molecules from the fluorophore environment to the bulk. Electrostatic binding of the dyes with polycarboxylate anions further restricts the rotational motions of the polymer chain in the case of cationic dyes. ${ }^{87}$

\subsection{Time resolved fluorescence investigation of the dyes bound to PMAA}

The fluorescence decay curves of $\mathrm{P}(\mathrm{MAA}-\mathrm{Ph})$ and $\mathrm{P}(\mathrm{MAA}-\mathrm{Th})$ in aqueous solutions are fitted satisfactorily with biexponential function independent of loading level of the dyes in the polymer. ${ }^{82}$ The bi-exponential 

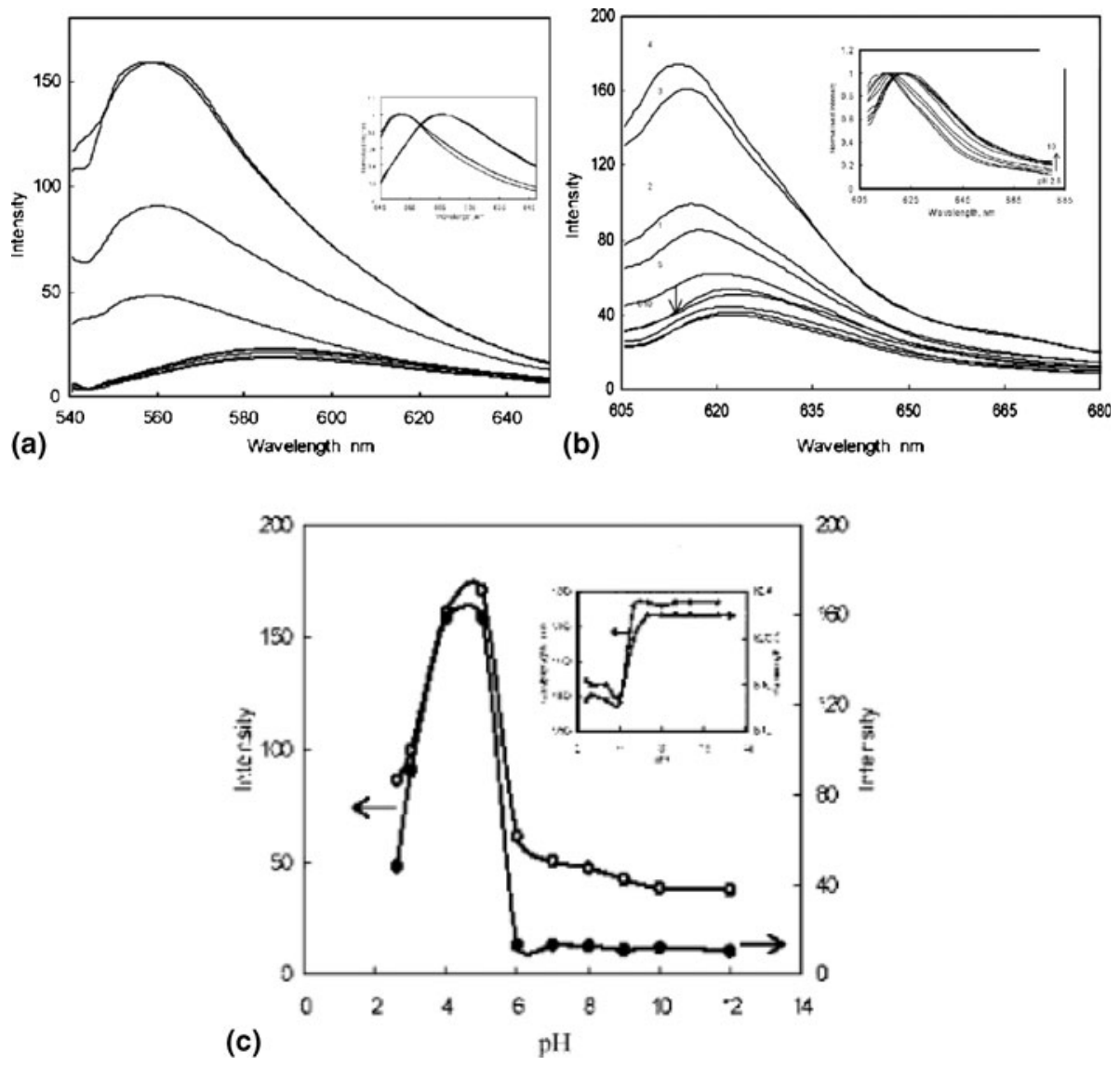

Figure 12. (a) Emission spectra of $\mathrm{P}(\mathrm{MAA}-\mathrm{Ph})$ Inset: Normalised emission spectra of $\mathrm{P}(\mathrm{MAA}-\mathrm{Ph})$ at various $\mathrm{pH}$. $\lambda_{\mathrm{em}}=520 \mathrm{~nm}$; concentration of the polymer: $1.0 \times$ $10^{-3}$ M. (b) Emission spectra of P(MAA-Th) at various pH. Inset: Normalised emission spectra of $\mathrm{P}(\mathrm{MAA}-\mathrm{Th})$ at different $\mathrm{pH}$. $\lambda_{\mathrm{em}}=590 \mathrm{~nm}$; concentration of the polymer: $1.0 \times 10^{-3} \mathrm{M}$. (c) Plot of $\mathrm{pH}$ vs shift in the emission maxima and the emission intensity. ${ }^{81}$
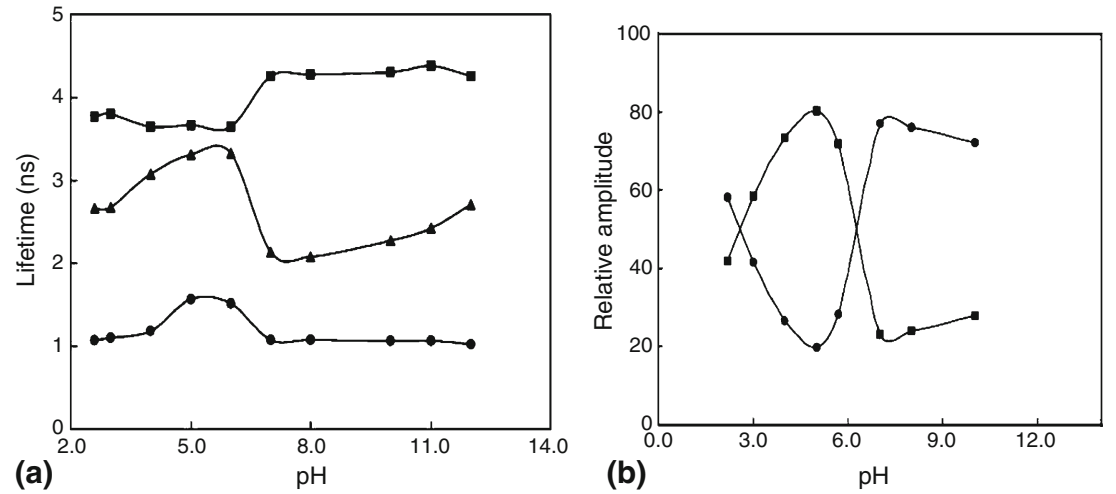

Figure 13. (a) Fluorescence lifetime of $\mathrm{P}(\mathrm{MAA}-\mathrm{Ph}) \mathrm{Vs} \mathrm{pH} ;\left(\lambda_{\mathrm{ex}}=295 \mathrm{~nm}\right.$; $\lambda_{\text {em }}=590 \mathrm{~nm}$; temperature $\left.=23.0 \pm 0.5^{\circ} \mathrm{C}\right) ;(\mathbf{b})$ The relative amplitude of $\mathrm{P}(\mathrm{MAA}-\mathrm{Ph}) \mathrm{Vs} \mathrm{pH}{ }^{81}$ 

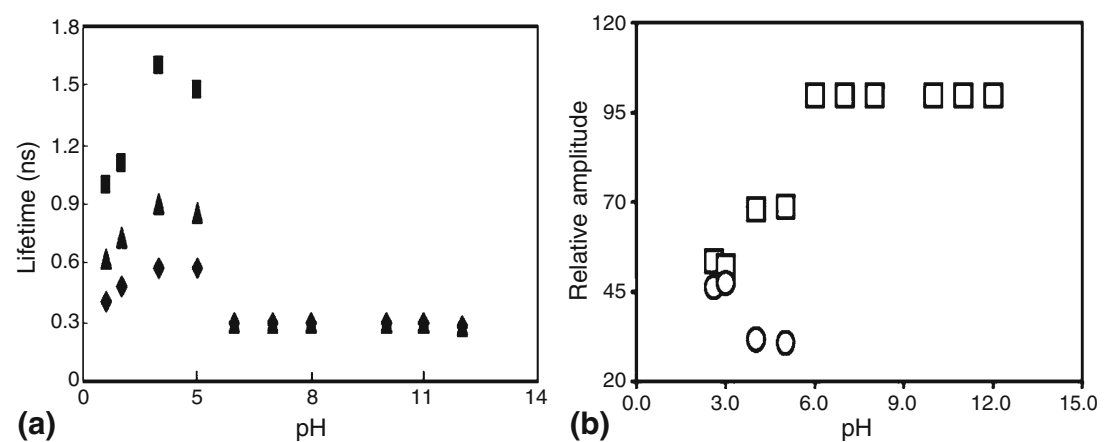

Figure 14. (a) Fluorescence lifetime of P(MAA-Th) Vs. (Concentration = $1.0 \times 10^{-3} \mathrm{M} ; \lambda_{\mathrm{ex}}=295 \mathrm{~nm} ; \lambda_{\mathrm{em}}=617 \mathrm{~nm}$; temperature $=23.0 \pm 0.5^{\circ} \mathrm{C}$. (b) The relative amplitude of $\mathrm{P}(\mathrm{MAA}-\mathrm{Th})$ Vs. $\mathrm{pH} .{ }^{80}$

decay of the $\mathrm{P}(\mathrm{MAA}-\mathrm{Ph})$ and $\mathrm{P}(\mathrm{MAA}-\mathrm{Th})$ is attributed to the presence of dyes in different microheterogeneous environment. As the $\mathrm{pH}$ increases, the average lifetime reduces to $1.55 \mathrm{~ns}$. The lifetime of $\mathrm{P}(\mathrm{MAA}-\mathrm{Ph})$ at $\mathrm{pH} 4.0$ is found to be the maximum and lower values are observed at more acidic or basic $\mathrm{pH}$ range. A bell-shaped curve was observed in the plot of the average lifetime of $\mathrm{P}(\mathrm{MAA}-\mathrm{Ph})$ against $\mathrm{pH}$ as shown in the figures $12 a$ and $b$. The relative amplitudes of the two lifetime components vary with increase in the $\mathrm{pH}$. The long-lived component increases gradually and reaches a maximum at $\mathrm{pH} 5.0$ and then it starts to decrease gradually and reaches to a minimum; a reverse trend was observed for the short-lived component and the amplitude of long-lived component is bell-shaped and has the maximum value at $\mathrm{pH}$ 5.0.

\subsection{Flash photolysis studies on the dynamics of PMAA using triplet state as probe in aqueous solution}

The absorption spectra of the transient observed on flash photolysis of PMAA bound phenosafranine under acidic conditions $(\mathrm{pH}<5.5)$ reveal the existence of both monoprotonated triplet and diprotonated triplet forms. ${ }^{88}$ It is noteworthy that the transient spectrum of triplet-triplet absorption of PMAA bound phenosafranine corresponding to the monoprotonated form shifts towards red region by $40 \mathrm{~nm}$ as compared to that of the free dye in aqueous solution. In the flash photolysis experiments, the observed maxima at $740 \mathrm{~nm}$ and $830 \mathrm{~nm}$ for the transient PMAA-PS ${ }^{+}$triplet are similar to that observed for the triplet state of the dye in acetonitrile. The absorption maximum observed at $680 \mathrm{~nm}$ is attributed to the diprotonated form of the triplet species. The decay monitored at the triplet absorption maximum does not fit into a single life time with first order kinetics. The best fit is obtained by fitting the decay using double exponential decay (60 $\mu \mathrm{s}(45 \%)$ and $530 \mu \mathrm{s}$ $(55 \%))$. The transient absorption spectrum recorded $10 \mu$ s after the laser pulse excitation of PMAA-PS ${ }^{+}$ solution at $\mathrm{pH} 2.7$ indicates the presence of monoprotonated and diprotonated triplet dye species almost in equal concentration. However at $\mathrm{pH} 4.5$, the absorbance corresponding to diprotonated form is reduced while the absorbance due to the presence of monoprotonated form is enhanced. The transient spectrum recorded at $\mathrm{pH} 7.3$ corresponds to the presence of diprotonated form. However, for the free dye in aqueous solution, the diprotonated triplet form is observed only up to $\mathrm{pH} 5.5$ and at higher $\mathrm{pH}$ the only observable form is the monoprotonated form of the triplet phenosafranine. In order to compare the manifestation of the polymer electrolyte PMAA on the properties of the triplet state of the dye,

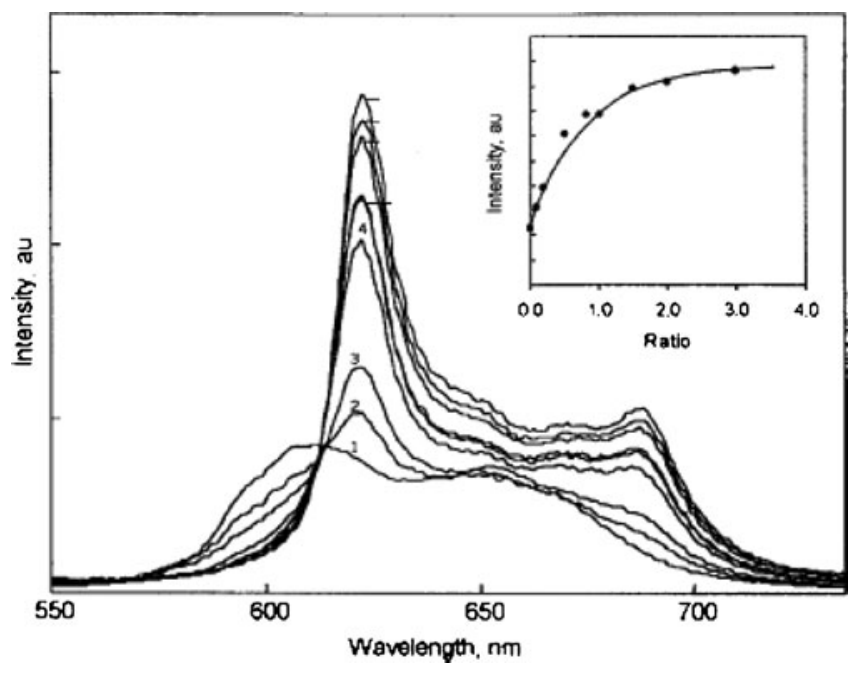

Figure 15. Enhancement in the emission intensity of $\mathrm{P}(\mathrm{MAAco}-\mathrm{PPIX})\left(2.0 \times 10^{-3} \mathrm{M}\right)$ on complexation with PVP at different ratio. ${ }^{89}$ 

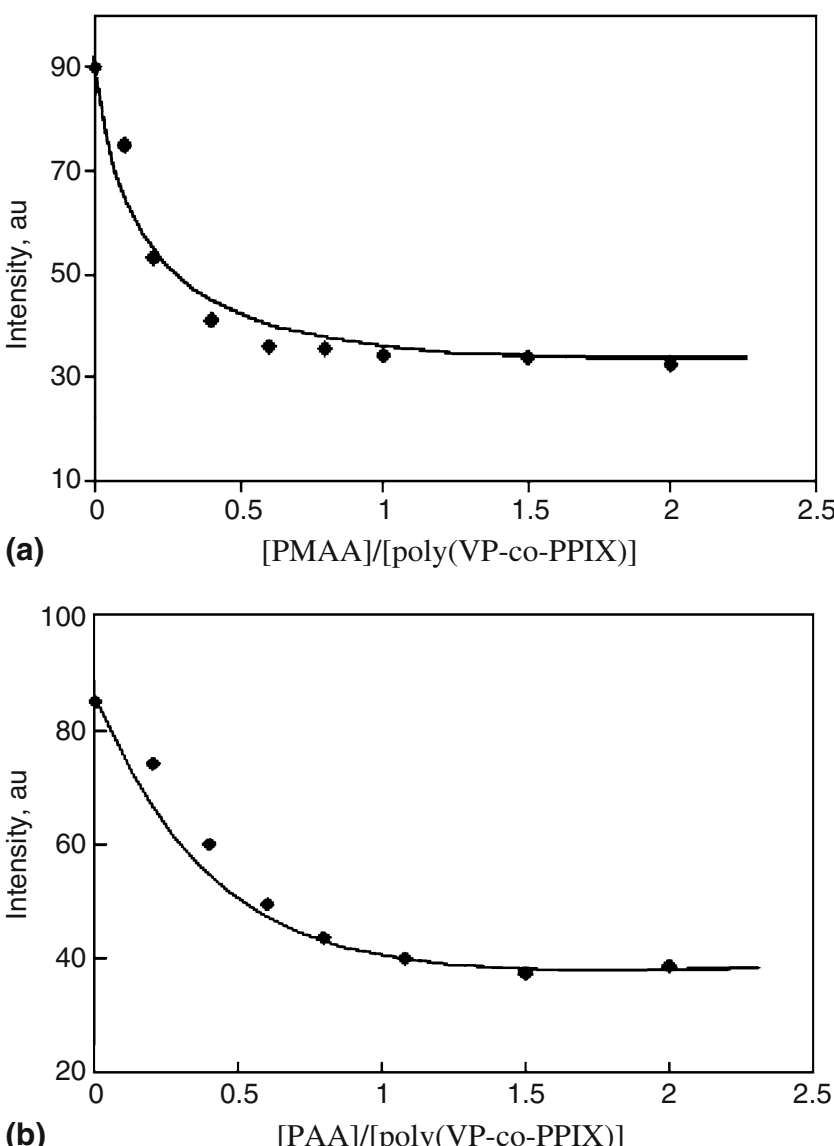

(b)

Figure 16. Change in the fluorescence intensity of P(VPco-PPIX) on interpolymer complexation with (a) PMAA; (b) PAA; concentration of polymer: $2 \times 10^{-3} ; \lambda_{\text {ex }}=400 \mathrm{~nm}$; $\mathrm{pH}=4.5 \pm 0.05$; temperature $=23.5 \pm 0.5^{\circ} \mathrm{C} .{ }^{89}$

the flash photolysis of phenosafranine bound to PAA in aqueous solution was studied. The characteristics of the transients observed for the phenosafranine bound to PAA on flash photolysis using $532 \mathrm{~nm}$ laser pulse is identical to that of the free dye in aqueous solution. The phenosafranine triplet bound to PMAA observed at $830 \mathrm{~nm}$ corresponds to the monoprotonated form in the less polar environment which shows a decrease in absorption on increasing the $\mathrm{pH}$ of the solution above $\mathrm{pH}=5.0$. The structure of PMAA is thus suggested to be more compact and less polar at $\mathrm{pH}<5$.0. The fluorophore is exposed to aqueous phase at higher $\mathrm{pH}$ (i.e., $\mathrm{pH}>6.0$ ) and the structural transition of PMAA from more compact to opened coils occurs at $\mathrm{pH}$ around 5.0 in aqueous solution.

\subsection{Self-organization of interpolymer adducts of $P M A A^{89,90}$}

Covalently bound protoporphyrin IX, PPIX, was used as a fluorophore to investigate the interpolymer complex formation between the poly(carboxylic acid)s, PMAA/PAA and poly(N-vinyl pyrrolidone), PVP, poly(ethylene oxide), PEO or poly(ethylene glycol), PEG. Absorption and emission spectral properties of protoporphyrin IX bound to PAA, PMAA and PVP have been studied. Protoporphyrin IX in P(MAAco-PPIX) was found to be present in the dimer or higher aggregated form at low $\mathrm{pH}$ due to the environmental restriction imposed by the polymer whereas in the case of $\mathrm{P}(\mathrm{AA}-\mathrm{co}-\mathrm{PPIX})$ and $\mathrm{P}(\mathrm{VP}-\mathrm{co}-\mathrm{PPIX})$, PPIX exists in monomeric form (figures 13, 14 and 15). The fluorescence intensity and lifetime of PPIX bound to poly(carboxylic acid)s increase on complexation through hydrogen bonding with PVP, PEO and PEG due to the displacement of water molecules in the vicinity of the PPIX. P(MAA-co-PPIX) shows longer fluorescence lifetime due to the more compact interpolymer complexation as compared to $\mathrm{P}$ (AA-co-PPIX) due to the enhanced hydrophobicity of PMAA. P(VPco-PPIX) shows a decrease in the fluorescence lifetime on complexation with PMAA or PAA due to the
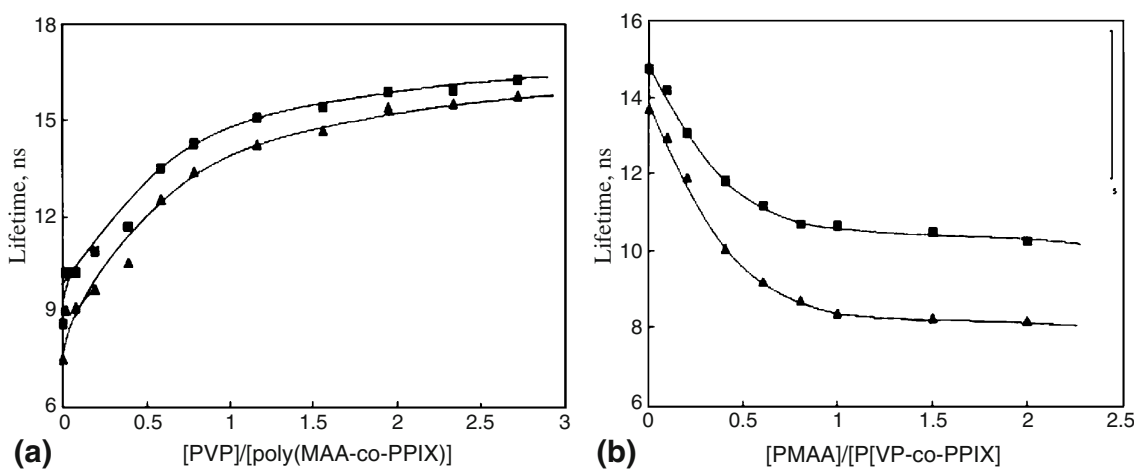

Figure 17. (a) Fluorescence lifetime of P(MAA-co-PPIX) on complexation with PVP and (b) Fluorescence lifetime of P(VP-co-PPIX) on complexation with PMAA. ${ }^{89}$ 
hydrophilic and micro gel-like environment of the fluorophore bound to PVP (figures 16 and 17). The contrasting behaviour of the same polymer adduct with respect to the site of the fluorophore is interpreted to be due to the solvent structure which determines the environment of the fluorophore.

\section{Conclusions}

The study of the relaxation processes from the electronic excited states is of interest to understand the electron and energy transfer pathways and reorganization of systems in biological and catalytic reactions. Often the reactions induced by electromagnetic radiation occurs from the excited states in fast time scale. During the course of the last three decades the time resolution has been achieved to measure chemical and physical events occurring in molecular and cluster systems even in femtosecond time domain. In particular the charge transfer in devices is known to be in ultrafast time scale and optimization of systems for energy applications and display systems is crucial for effective applications. In nanomaterial chemistry and in biological molecules the excited processes involve several other states and transients and the identification of the individual pathways has been made possible with the use of ultrafast laser systems. In this review article the excited state reactions of many coordination compounds and dyes are discussed essentially with reference to the facilities developed to investigate the ultrafast processes over the years at the University of Madras.

\section{Acknowledgements}

The award of Raja Ramanna Fellowship from the Department of Science and Technology (DST) and Indian National Science Academy (INSA) Senior Scientist position to $\mathrm{P} \mathrm{N}$ is acknowledged. The financial assistance for the investigations is provided by DST IRHPA, DST-SERC and Council of Scientific and Industrial Research (CSIR) projects. KD thanks CSIR for senior research fellowship.

Abbreviations
$\begin{array}{ll}\mathrm{TiO}_{2} & \text { Titanium dioxide } \\ \mathrm{ZnO} & \text { Zinc oxide } \\ \mathrm{NCUFP} & \text { National Centre for Ultrafast Processes } \\ \text { Bpy } & 2,2^{\prime} \text {-bi pyridine }\end{array}$

CTTS Charge transfer to solvent

Gly

Triene

Glycine

N, N'-bis-(2-aminoethyl)-1,2ethanediamine

Tetraen N-(2-aminoethyl)-N'-[2-(2-aminoethyl) aminoethyl]-1,2-ethanediamine

tet-a 5,7,7,12,14,14-hexamethyl-1,4,8,11tetraazacyclo tetradecane

Htcd

AT

5,7,7,12,14,14-hexamethyl-1,4,8,11tetraazacyclotetradeca-4,11-diene

AT = 11,13-dimethyl-1,4,7,10tetraazacyclotrideca-10,12-dienato

BG-opdn 4,9-dihydroxy-3,4,9,10-tetraphenyl-6, 7-benzo-1,2,5,8,11, 12-hexaazacyclotetradeca-2,6,10,12, 14-pentaene

ZSM-5 Zeolite socony mobil - 5

MCM-41 Mobile Crystalline Materials - 41

$\mathrm{PS}^{+} \quad$ Phenosafranine

${ }^{3} \mathrm{PSH}^{2+} \quad$ Protonated phenosafranine triplet

AGA Acrylamido glycolic Acid

ITO Indium doped tin oxide

En Ethylenediamine

PVP Poly(vinylpyridine)

P(MAAM) Poly(methylolacrylamide)

VP Vinylpyridine

P(MAA)-Ph Poly(methacrylic acid) - phenosafranine

P(MAA)-Th Poly(methacrylic acid)- thionine

PAA

PPIX

PEO

MB

Th

Poly(acrylic acid)

Protoporphyrin-IX

Poly(ethylene oxide)

Methylene blue

Thionine

\section{References}

1. Turro N J, Ramamurthy V and Scaiano J C 2010 Modern molecular photochemistry of organic molecules (Sausalito, CA: University Science Books)

2. Suppan P 1994 Chemistry and light (London: The Royal Society of Chemistry)

3. Renger G 2008 Primary processes of photosynthesisPart 1 (Cambridge: RSC)

4. Renger G 2008 Primary processes of photosynthesisPart 2 (Cambridge: RSC)

5. Blankenship R 2002 Molecular mechanisms of photosynthesis (St Louis, MO: Washington University)

6. Balzani V and Scandola F 1991 Supramolecular photochemistry (New York: Ellis Horwood)

7. Lakowicz J R 1999 Principles of fluorescence spectroscopy (New York: Kluwer Academic/Plenum Publishers)

8. Adamson A W 1975 Concepts of inorganic photochemistry (New York: Wiley-VCH) 
9. (a) Lewis G N, and Kasha M 1945 J. Am. Chem. Soc. 67 994; (b) Henry B R and Kasha M 2003 J. Phys. Chem. A 107 6738; (c) Catalan J, Perez P, Del V, Juan C, De Paz J L G and Kasha M 2002 Proc. Natl. Acad. Sci. USA 99 5793; (d) Kasha M 1999 Act. Phys. Pol. A 9515

10. Birks J B 1970 Photophysics of aromatic molecules (New York: Wiley-Interscience)

11. Klán P and Wirz J 2009 Photochemistry of organic compounds: From concepts to practice (John Wiley \& Sons, Inc)

12. Kutateladze A G 2005 Computational methods in photochemistry (Boca Raton, USA: CRC Press)

13. Caldin E F 2001 Mechanisms of fast reactions in solution (Amsterdam, The Netherlands: IOS Press)

14. Zewail H 1994 Femtochemistry: Ultrafast dynamics of the chemical bond (World Scientific Publishing Co. Pte. Ltd) vols I \& II

15. Fleming G R 1986 Chemical applications of ultrafast spectroscopy (Oxford: Oxford University Press)

16. Fox M A 1988 Photoinduced electron transfer (Amsterdam: Elsevier)

17. Ramamurthy V and Schance K S 1999 Multimetallic and macromolecular inorganic photochemistry (New York: Marcel Dekker)

18. Ariga K, Kunitake T 2006 Supramolecular chemistry Fundamentals and applications. (Heidelberg: Springer Verlag)

19. Stroscio M A and Dutta M (eds) 2004 Biological nanostructures and applications of nanostructuresin biology (Springer)

20. Valeur B 2002 Molecular fluorescence: Principles and applications (Weinheim: Wiley-VCH)

21. (a) Lehn J-M 1998 Supramolecular chemistry: Concepts and perspectives (Weinheim: Wiley-VCH); (b) Pastore M, Mosconi E, De Angelis F and Grätzel M A 2010 J. Phys. Chem. C 114 7205; (c) Peter M L 2011 J. Phys.Chem. Lett. 1861

22. Adamson A W and Demas J N 1971 J. Am. Chem. Soc. 931800

23. Natarajan P and Endicott J F 1973 J. Am. Chem. Soc. 95 2470

24. Gafney H D and Adamson A W 1972 J. Am. Chem. Soc. 948238

25. Chandrasekaran K and Natarajan P 1980 Inorg. Chem. 191714

26. Chandrasekaran K and Natarajan P 1981 J. Chem. Sci. Dalton Trans. 478

27. Natarajan E and Natarajan P 1992 Inorg. Chem. 31 1215

28. Natarajan P and Raghavan N V 1980 J. Am. Chem. Soc. 1024518

29. Dhanasekaran T and Natarajan P 1992 J. Am. Chem. Soc. 1144621

30. Natarajan P and Raghavan N V 1980 Chem. Commun. 268

31. Prakash H and Natarajan P 2003 Res. Chem. Intermed. 29349

32. Yamaguchi H, Fujiwara R and Kusuda K J 1987 J. Macromol Sci. Chem. 24367

33. Morris J B and Johnston M V 1986 Int. J. Mass Spectrom., Ion Process. 73175
34. Prakash H and Natarajan P 2000 Chem. Phys. Lett. 329 357

35. Prakash H and Natarajan P 2003 Inorg. Chem. Commun. 61071

36. Dhanasekaran T, Prakash $\mathrm{H}$ and Natarajan P $2001 \mathrm{~J}$. Photochem. Photobiol. A: Chem. 14117

37. Palaniappan $\mathrm{S}$, Jothivenkatachalam $\mathrm{K}$ and Natarajan $\mathrm{P}$ 2001 Inorg. Chem. Commun. 4738

38. Dutta P K and Severance M 2011 J. Phys. Chem. Lett. 2 467

39. Shim T, Lee M H, Kim D, Kim H S and Yoon K B 2009 J. Phys. Chem. B 113966

40. Ide Y, Matsuoka M and Ogawa M $2010 \mathrm{~J}$. Am. Chem. Soc. 13216762

41. Senthilkumar K, Paul P, Selvaraju C and Natarajan P 2010 J. Phys. Chem. 1147085

42. Fujii K, Iyi N and Hashizume H 2009 Chem. Mater. 21 1179

43. Easwaramoorthi S and Natarajan P 2005 Micro Meso Mater. 86185

44. Easwaramoorthi S and Natarajan P 2009 Micro Meso Mater. 117541

45. Ananthanarayanan K and Natarajan P 2009 Micro Meso Mater. 117541

46. Ananthanarayanan K, Selvaraju C and Natarajan P 2007 Micro Meso Mater 99319

47. Cenens J, Schoonheydt R A 1998 Clays and Clay Mine 36214

48. Senthil Kumar K 2011 Ph.D Thesis, University of Madras

49. Corma A, Fornes V, Galletero M S, Garcia H and Scaiano J C 2002 Chem. Commun. 334

50. Tamilarasan R and Natarajan P 1981 Nature 292 224

51. Bhowmik B Mukhopadhyay B and Mausumi $1994 J$. Photochem. Photobiol. A: Chem. 78173

52. Tamilarasan R and Natarajan P 1981 Indian J. Chem. 20A 213

53. Tamilarasan R and Natarajan P 1981 Curr. Sci. 50713

54. Ramaraj R and Natarajan P 1989 J. Chem. Soc. Faraday Trans. 85(4) 813

55. Viswanathan K and Natarajan P 1996 J. Photochem. Photobiol. A: Chem. 95255

56. Balasubramaniam E and Natarajan P 1997 J. Photochem Photobiol. A: Chem. 10939

57. Viswanathan K and Natarajan P 1997 Proc. INSA Part A Phys. Sci. 2129

58. Albery J W 1982 Acc. Chem. Res. 15142

59. Barsukov V Z, Khomenko V G, Chivikov S V, Barsukov I V and Motronyuk T I 2001 Electrochim. Acta 464083

60. Li L, Chow W C, Wong W Y, Chui C H, Wong R S M 2011 J. Organomet. Chem. 6961189

61. Deng X, Zheng L, Yang C, Li Y, Yu G and Cao Y 2004 J. Phys. Chem. B 1083451

62. Narayanan V and Natarajan P 1992 J. Polym. Sci. Part A Polym. Chem. Ed. 302475

63. Tamilarasan R and Natarajan P 1981 Indian J. Chem. 20A 1149

64. Tamilarasan R and Natarajan P 1982 'Solar World Forum', 2204. Eds D O Hall J Morton, Pergamon Press 
65. Ramaraj R and Natarajan P 1989 Indian J. Chem. 28A 187

66. Arunachalam S and Natarajan P 1983 J. Chem. Soc. Chem. Comm. 472

67. Ramaraj R, Tamilarasan R and Natarajan P $1985 \mathrm{~J}$. Chem. Soc. Faraday Trans. 812763

68. Ramaraj R and Natarajan P 1985 Chem. Phys. Lett. 113 108

69. Natarajan P 1988 J. Macromol. Sci. Chem. A25 128

70. Ramaraj R and Natarajan P 1991 J. Polym. Sci. Part A, Polym. Chem. Ed. 291339

71. Anbalagan K and Natarajan P 1991 J. Polym. Sci. Part A Polym. Chem. Ed. 291739

72. Viswanathan K and Natarajan P 1996 J. Photochem. Photobiol. A: Chem. 95245

73. Balasubramaniam E and Natarajan P 1996 J. Photochem. Photobiol. A: Chem. $\mathbf{1 0 3} 201$

74. Flory P 1953 J. Principles of Polymer Chem. (Ithaca, NY: Cornell University Press)

75. Olea A F and Thomas J K 1989 Macromolecules 22 1165

76. Horsky J and Morawetz H 1988 Macromol. Chem. 189 2475

77. Olea A F, Rosenbluth H and Thomas J K 1999 Macromolecules 328077
78. Morawetz H 1991 J. Polym. Sci. Part A Polym. Chem. 37 1725 and references cited therein

79. Synak A, Ziǒłek M, Organero J A and Douhal A $2010 \mathrm{~J}$. Phys. Chem. B 11416567

80. Soutar I, Swanson L, Imhof R E and Rumbles G. 1992 Macromolecules 1254399

81. Natarajan P and Raja C 2005 Eur. Polym. J. 41 2496

82. Anufrieva E V, Birstein T M, Nekrasoava T N, Ptitsyn O B and Sheveleva T V 1968 J. Polym. Sci. Part C 16 3519

83. Pereira R V and Gehlen M H 2006 J. Phys. Chem. B 110 6537

84. Bednăŕ B, Morawetz H and Shafer J A 1985 Macromolecules 181940

85. Mirenda M, Dicelio L E and Román E S 2008 J. Phys. Chem. B 11212201

86. Košovan P, Limpouchová Z and Procházka K 2006 Macromolecules 393458

87. Natarajan P and Raja C 2004 Eur. Polym. J. 402291

88. Durai Murugan K and Natarajan P 2011 Eur. Polym. J. doi:10.1016/j.eurpolymj.2011.05.018

89. Raja C, Ananthanarayanan K and Natarajan P 2006 Eur. Polym. J. 42495

90. Natarajan P and Raja C 2001 Eur. Polym. J. 372207 